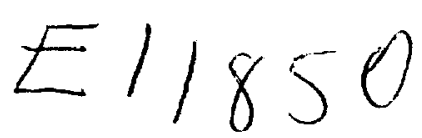

Twenty-Seventh Symposium (Intemational) on CombustionThe Combustion Institute, 1994/pp. 2455-2506

\title{
1400304 \\ UNDERSTANDING COMBUSTION PROCESSES THROUGH MICROGRAVITY RESEARCH
}

\author{
PAUL D. RONNEY \\ Department of Aerospace and Mechanical Engineering \\ University of Southern Califormia \\ Los Angeles, CA 90089-1453, USA
}

\begin{abstract}
A review of research on the effects of gravity on combustion processes is presented, with an emphasis on a discussion of the ways in which reduced-gravity experiments and modeling has led to new understanding. Comparison of time scales shows that the removal of buovancy-induced convection leads to manifestations of other transport mechanisms, notably radiative heat transfer and diffusional processes such as Lewis number effects. Examples from premixed-gas combustion, non-premixed gas-jet flames, droplet combustion. flame spread over solid and liquid fuels, and other fields are presented. Promising directions for new research are outlined, the most important of which is suggested to be radiative reabsorption effects in weakly burning flames.
\end{abstract}

\section{Introduction}

Gravity influences many combustion processes, particularly due to buoyant convection which affects transport of thermal energy and reactants to and from the chemical reaction zones. Recently, many experimental and theoretical studies of combustion at microgravity $(\mu \mathrm{g})$ conditions have been conducted. These studies are motivated by the need to assess fire hazards in spacecraft and to enable better understanding of combustion processes at earth gravity ( $1 g$ ) through the elimination of buoyancy [1-4].

This paper discusses how new understanding of combustion processes has been obtained through $\mu \mathrm{g}$ research, rather than providing a comprehensive review of this rapidly changing field. First, comparisons of time scales for various chemical and transport processes in flames, including buoyancyinduced transport, are given. Next, examples of unexpected results and new understandings obtained through $\mu \mathrm{g}$ research are discussed. These findings are then summarized and future research directions are suggested.

\section{Comparison of Time Scales for Premixed-Gas Combustion}

To determine the conditions in which gravity can affect flames, the estimated time scales for chemical reaction $\left(t_{\text {chem }}\right)$, inviscid buoyant convection $\left(t_{\text {inv }}\right)$, viscous buoyant convection $\left(t_{\text {vis }}\right)$, conductive heat loss to walls ( $\left.t_{\text {cond }}\right)$, and radiant heat loss $\left(t_{\text {rad }}\right)$ are compared. Premixed laminar flames are considered first because of their simplicity. Subsequent sections introduce time scales for other flames.
The chemical time scale is (see Nomenclature) $t_{\text {chem }} \approx \delta / S_{\mathrm{L}}$ where $\delta=\alpha / S_{\mathrm{L}}$, thus $t_{\text {chem }} \approx \alpha / S_{\mathrm{L}}^{2}$. The convective transport time scale is $d / U$, where $d$ is a characteristic flow length scale, $U \approx(\operatorname{gd}(\Delta \rho / \rho))^{1 / 2}$ is the buoyant convection velocity, and $\Delta \rho$ the density change across the Bame. Because $\Delta \rho / \rho \approx 1$ for flames, $t_{\mathrm{inv}} \approx d /(g d)^{1 / 2}=(d / g)^{1 / 2}$. For inviscid flow; $d$ is determined by the apparatus dimensions, for example the burner or tube diameter. For viscous flow, $d$ cannot be specified independently; instead $d$ $\approx v / U$, thus $U \approx(g v)^{1 / 3}$ and $t_{\mathrm{vis}} \approx d / U \approx(v / U) / U \approx$ $\left(v / g^{2}\right)^{1 / 3}$ the conduction time scale $t_{\text {cond }}$ is the flame front temperature $\left(T_{f}\right)$ divided by the rate of temperature decrease due to conductive loss; thus $t_{\text {cond }}$ $=T_{\mathrm{f}} /(d T / d t) \approx T_{\mathrm{f}} /\left(\rho C_{\mathrm{p}} h\left(T_{\mathrm{f}}-T_{\mathrm{x}}\right)\right)$; thus $t_{\text {cond }} \approx$ $d^{2} / 16 \alpha$. Similarly, for optically thin radiation, $t_{\text {rad }} \approx$ $T_{f} /\left(\Lambda / \rho C_{\mathrm{P}}\right)=\{\gamma /(\gamma-1)\}\left(P / 4 \sigma a_{\mathrm{P}}\left(T_{f}^{4}-T_{x}^{4}\right)\right\}$.

Two sets of time scales are shown in Table 1, one for near-stoichiometric hydrocarbon-air flames and one for near-limit flames, both at $P=1$ atm. For near-stoichiometric flames $S_{\mathrm{L}} \approx 0.40 \mathrm{~m} / \mathrm{s}, T_{\mathrm{f}} \approx 2200$ $K, \alpha \approx v 1.5 \times 10^{-4} \mathrm{~m}^{2} / \mathrm{s}$ and $a_{\mathrm{P}} \approx 0.56 \mathrm{~m}^{-1}$. For near-limit flames, $S_{\mathrm{L}} \approx 0.02 \mathrm{~m} / \mathrm{s}, T_{\mathrm{f}} \approx 1500 \mathrm{~K}, \alpha \approx$ $\nu \approx 1.0 \times 10^{-4} \mathrm{~m}^{2} / \mathrm{s}$ and $a_{\mathrm{p}} \approx 0.83 \mathrm{~m}^{-1}$. For both cases $g=9.8 \mathrm{~m} / \mathrm{s}^{2}, \gamma \approx 1.35, T_{x} \approx 300 \mathrm{~K}$ and $d \approx$ $0.05 \mathrm{~m}$ (a typical apparatus dimension.)

Several observations can be made on the basis of these simple estimates:

1. Buoyant convection is unimportant for near-stoichiometric flames because $t_{\mathrm{vis}} \gg t_{\text {chem }}$ and $t_{\mathrm{i}, \mathrm{w}} \gg$ $t_{\text {chem }}$

2. Buoyant convection strongly influences near-limit flames at $\mathrm{lg}$ because $t_{\text {vis }} \leq t_{\text {chem }}$ and $t_{\text {inv }} \leq t_{\text {chem. }}$.

3. Radiation effects are unimportant at $\mathrm{lg}$ compared to buoyant convection because $t_{\text {sis }} \ll t_{\text {rad }}$ and $t_{\text {inv }}$ $\ll t_{\text {rad }}$. 
TABLE 1

Estimates of time scales for strichiometric and nearlimit hudrocarbon-air Hames at $L$ atm pressure

\begin{tabular}{|c|c|c|}
\hline Time Scale & $\begin{array}{c}\text { Stoichiometric } \\
\text { Flame }\end{array}$ & $\begin{array}{l}\text { Near-Limit } \\
\text { Flame }\end{array}$ \\
\hline Chemistgn $\left(t_{1} \cdot 1+\cdots\right)$ & 1).010094s & $0.25 \mathrm{~s}$ \\
\hline Buoyant. inviscid $\left(t_{m, n}\right)$ & $0.071 \mathrm{~s}$ & $0.071 \mathrm{~s}$ \\
\hline Buovant, viscous $\left(t_{1 \mathrm{w}}\right)$ & $0.012 \mathrm{~s}$ & $0.010 \mathrm{~s}$ \\
\hline $\begin{array}{l}\text { Conduction to tube wall } \\
\left(t_{\text {contut }}\right) \\
\text { Radiation }\left(t_{\text {rau }}\right)\end{array}$ & $\begin{array}{l}0.9 .5 \mathrm{~s} \\
0.1 .3 \mathrm{~s}\end{array}$ & $\begin{array}{l}1.4 \mathrm{~s} \\
0.41 \mathrm{~s}\end{array}$ \\
\hline
\end{tabular}

4. Radiation effects dominate near-limit flames because $t_{\text {rad }} \approx t_{\text {cliem }}$, but these effects are only observable at reduced gravity because of observation 3.

5. The apparatus size $(d)$ must be larger than about $0.03 \mathrm{~m}$ to observe radiation-induced extinction; otherwise, conduction losses exceed radiative losses $\left(t_{\text {tund }}<t_{\text {rasid }}\right)$.

6. Many radiative loss effects can be studied in drop-towers (test duration 2-10 s), because these times are typically larger than $t_{\mathrm{rad}}$

7. Because $t_{\mathrm{im}} \sim \mathrm{g}^{1 / 2}$ and $t_{\mathrm{tis}} \sim \mathrm{g}^{1 / 3}$, aircraft-based $\mu g$ experiments at $g \approx 10^{-2} g_{0}$ may not provide sufficiently reduced buoyancy to observe radiative effects.

8. Because $t_{\mathrm{its}} \sim v^{1 / 3} \sim P^{-1 / 3}$ and $t_{\mathrm{rad}} \sim \rho / \Lambda \sim$ $P^{1} / P^{1} \sim P^{0}, t_{\mathrm{vis}} / t_{\mathrm{rad}} \sim P^{-1 / 3}$. Thus, $t_{\mathrm{rad}}$ is independent of $P$, but at higher $P$, buoyancy effects interfere more strongly with radiative effects.

9. A Reynolds number $R e_{d} \equiv U d / v$ for buoyant flow is estimated as $(g d)^{1 / 2} d / v^{2}=G r_{d}^{1 / 2}$, where $G r_{d}=$ $g d^{3} / v^{2}$ is a Grashof number. For $R e_{d d} \geq 10^{3}$, thus $G r_{d} \geq 10^{6}$, buoyant fow at $\mathrm{lg}$ is generally turbulent, thus, it difficult to obtain steady laminar flames in large systems at $1 g$.

The implications of these observations are discussed in the following sections. Essentially, any combustion process where $t_{\text {chem }}$ or $t_{\text {rad }}$ exceeds $t_{\text {inv }}$ or $t_{\text {vis }}$ may be affected by gravity and is worthy of $\mu \mathrm{g}$ investigation.

\section{Premixed Gas Flames}

\section{Flammability Limits}

The previous section showed that gravity effects are significant only for mixtures with low $S_{\mathrm{L}}$, implying mixtures highly diluted with excess fuel, oxidant, or inert gas, but sufficient dilution causes flammability limits. Thus, gravity effects have significant influences on near-limit behavior, which is expected since limits are different for upward, dommward, and horizontal propagation [5].

Practically all flammability limit studies show that burming velocity at the flammability limit $\left(S_{1}\right)$ is nonzero. Giovangigli and Smooke [6] have shown that there is no purely chemical Aammability limit criterion for planar unstretched fames: without losses, $S_{\mathrm{I}}$ decreases asymptotically to zero as dilution increases. Consequently, loss mechanisms such as those discussed below are needed to explain limit mechanisms. The resulting predictions of $S_{I \text { limin }}$ indicate that $S_{L, \text { lim }}$ usually depends only weakly on chemical reaction rate parameters. Thus, limit mechanisms may be inferred by comparing predicted and measured $S_{L, \text { lim }}$ without detailed chemical knowledge. The mixture composition at the linit affects $S_{\mathrm{L} \text { lim }}$ only weakly through $T_{\mathrm{f}}$ : thus, comparing predicted and measured limit compositions is not especially enlightening; comparisons of $S_{L . \text { lim }}$ values is much more useful. Consequently, this discussion emphasizes comparisons of predicted and measured values of $S_{\mathrm{L}, \mathrm{lim}}$.

For upward propagation, Levy [7] showed that the flame rise speed at the limit $\left(\approx 0.33(\text { gd })^{1 / 2}\right)$ is identical to that of an inviscid hot gas bubble. This relation was later verified for a wide range of tube diameters and mixtures [8]. Buckmaster and Mikolaitis [9] showed how this minimum rise speed causes hydrodynamic strain at the Aame tip, which causes extinguishment for sufficiently low $S_{L}$. The predicted burming velocity of the limit mixture $\left(S_{\mathrm{L}, \mathrm{lim}}\right)$ is, after temperature-averaging transport properties:

$$
S_{\mathrm{L}, \mathrm{lim}}=2.8 \exp \left[\frac{\beta}{4}\left(1-\frac{1}{\mathrm{Le}}\right)\left(1-\frac{T_{*}}{T_{\mathrm{f}}}\right)\right]\left(\frac{g \alpha^{2}}{d}\right)^{1 / 4}
$$

The form of equation $1, S_{\text {L.lim }} \sim\left(g \alpha^{2} / d\right)^{1 / 4}$, can be obtained by setting $t_{\mathrm{inv}}=t_{\text {chem }}$.

For downward propagation in tubes, centrifuge experiments [10] indicate that $S_{L, l i m} \sim g^{1 / 3}$, independent of $L e$, which is reasonable since downwardpropagating near-limit flames are nearly flat and unstrained. Experiments [11] and numerical simulations [12] suggest extinction results from sinking regions of cooling burned gas near the walls overtaking the flame and blocking it from fresh reactants, although the $g^{1 / 3}$ scaling was not tested in Refs. $[11,12\}$. The $g^{1 / 3}$ scaling can be obtained by setting $t_{\text {chem }}=t_{\mathrm{vis}}$, thus

$$
S_{\mathrm{L}, \lim } \sim(\mathrm{g} \alpha)^{1 / 3}
$$

Experiments [8] employing varying diluent gases and pressures confirm the $\alpha^{1 / 3}$ scaling and lack of dependence on tube size, which, together with the $\mathrm{g}^{1 / 3}$ scaling mentioned above, supports the proposed mechanism.

Both upward- and downward-limit mechanisms indicate that as $g \rightarrow 0, S_{\text {L.tim }} \rightarrow 0$, implying arbitrarily 


\section{$\therefore$}

.




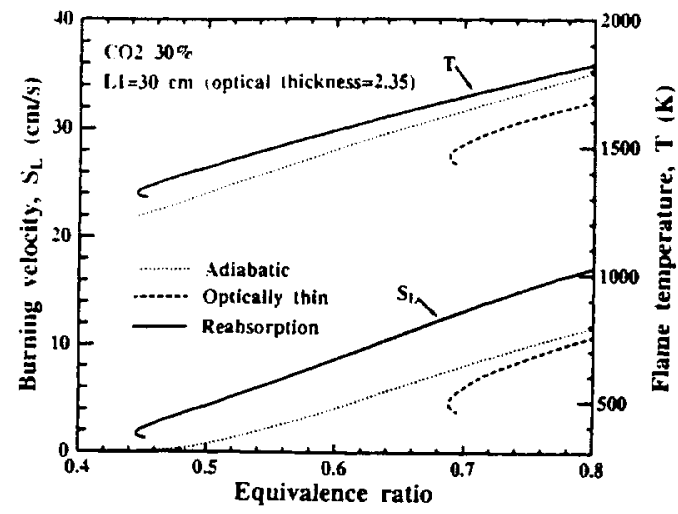

FIC. 1. Predicted values of buming velocity and peak Hame temperature in $\mathrm{CH}_{4}-\left(0.21 \mathrm{O}_{2}+0.49 \mathrm{~N}_{2}+0.30\right.$ $\mathrm{CO}_{2}$ mixtures under adjabatic conditions, with optically thin radiative losses and including reabsorption effects [26].

weak mixtures could burn very slowly. However, conductive or radiative losses prevent arbitrarily weak mixtures from burning even at $g=0$. Theories that relate flammability limit to heat losses [13-15] predict a minimum $T_{\mathrm{f}}$ below which flame propagation cannot occur because chemical reaction rates are much stronger functions of temperature than heat loss rates (exponential vs. algebraic). Consequently, because dilution decreases $T_{f}$, dilution increases the impact of losses, leading to flammability limits. For conductive losses, setting $t_{\text {chem }}=t_{\text {cond }}$ leads to

$$
P e_{\text {lim }} \equiv S_{\mathrm{L} . \mathrm{lim}} d / \alpha=\text { constant }
$$

with experiments $[8,16]$ and computations $[17]$ indicating $P e_{\text {lim }} \approx 40$. For radiative losses, setting $t_{\text {chem }}$ $=t_{\text {rad }}$ leads to $[18,19]$

$$
S_{\mathrm{L}, \mathrm{lin}}=\frac{1}{\rho_{x} C_{p}} \sqrt{\frac{1.2 \beta A \lambda_{f}}{T_{f}}}
$$

For lean-limit $\mathrm{CH}_{4}$-air mixtures at 1 atm, equation 4 yields $S_{\mathrm{L}, \text { im }} \approx 0.023 \mathrm{~m} / \mathrm{s}$, similar to detailed numerical model predictions $[20,21]$. Such small $S_{\mathrm{L} \text {,lin }}$ are not observed at $\mathrm{l} g$ because of buoyant convection $\left(t_{\text {inv }}<t_{\text {rad }}\right.$ and $\left.t_{\text {sis }}<t_{\text {rad }}\right)$; equations 1 and 2 yield $S_{\text {L.lim }} \approx 0.033$ and $0.078 \mathrm{~m} / \mathrm{s}$ for upward and downward propagation, respectively. At $\mu g$, however, predictions of equation 4 compare favorably to experiments in large combustion vessels $[19,22]$ using varying pressures, fuels, and inert gases. Also, similar results were obtained for $\mathrm{CH}_{4}$-air mixtures at $\mathrm{l}$ atm in tubes with $d=0.05 \mathrm{~m}$ [23], suggesting these limits are apparatus-independent. Thus, radiative losses may cause flammability limits when extrinsic losses (conduction, buoyant convection, etc.) are eliminated. In this instance, $\mu g$ experiments enabled observation of phenomena not observable at $\mathrm{lg}$.
These radiative effects apply only for opticilly thin gases (i.e., no reabsomtion of emitted radiation), which are inappropizate for large systems. high pressures, or mixtures with strongly absorbing material. With this motivation, $\mu g$ experiments [24] were conducted using lean $\mathrm{CH}_{4}$-air mixtures seeded with $\mathrm{SiC}$ particles. Because solids emit/absorb as black- or grav-hodies, whereas gases radiate in narrow spectral hands, particle-seeded gases emit/absorb more radiation than particle-free gases. Measurements of propagation rates, pressures and postllame thermal decays showed that, consistent with theoretical predictions [25], at low particle loadings the particles increase radiative loss (optically thin conditions), whereas at higher loadings reabsorption of emitted radiation becomes significant, which decreases net radiative loss and augments conductive heat transport.

Even for gases, computations [26] using detailed statistical narrow-band radiation models show that flammability limits are extended considerably with reabsorption (Fig. 1). With gases, however, two mechanisms lead to flammability limits even with reabsorption. One is the difference in composition between reactants and products; if $\mathrm{H}_{2} \mathrm{O}$ or other radiatively active combustion products are absent from the reactants, radiation from these species that is emitted upstream cannot be reabsorbed by the reactants. The second mechanism is that emission spectra are broader at $T_{\mathrm{f}}$ than $T_{\mathrm{x}}$; thus, some radiation emitted near the flame front cannot be absorbed by the reactants. Upstream loss occurs via both mechanisms, leading to extinction of weak mixtures. These results suggest that fundamental (domainand gravity-independent) flammability limits due to radiative losses may exist at $\mu \mathrm{g}$, but these limits are strongly dependent on emission/absorption spectra of reactant and product gases and their temperature dependence and cannot be predicted using gray-gas or optically-thin model parameters.

\section{Stretched Flames}

Premixed gas flames generally are not flat and steady nor do they propagate into quiescent flows. Consequently, flames are subject to "flame stretch," $\Sigma \equiv(1 / A)(d A / d t)[18]$, which affects $S_{\mathrm{L}}$ and extinction conditions $[18,27]$. At $1 \mathrm{~g}$, buoyancy imposes flame stretch comparable to $t_{\text {inv }}^{-1}$ or $t_{\text {iis }}^{-1}$. At $\mu \mathrm{g}$, weak flame stretch effects that are insignificant at $\mathrm{lg}$ may dominate. One example is expanding spherical flames for which

$$
\Sigma \equiv \frac{1}{A} \frac{d A}{d t}=\frac{1}{4 \pi r_{f}^{2}} \frac{d}{d t}\left(4 \pi r_{\mathrm{f}}^{2}\right)=\frac{2}{r} \frac{d r_{\mathrm{f}}}{d t}
$$

For $L e<1$, positive stretch increases $T_{\mathrm{r}}$ because the increased chemical enthalpy diffusion to the flame front in the form of scarce reactant exceeds the increased thermal enthalpy loss. Because heat release

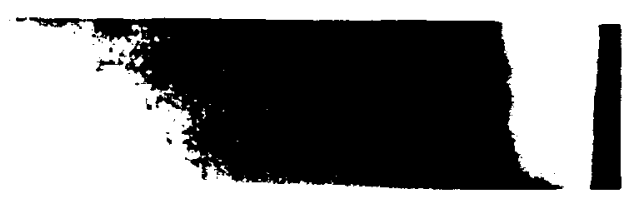




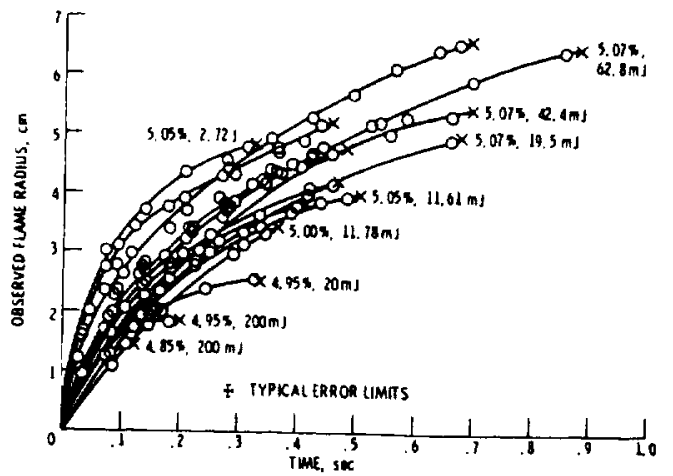

FIC. 2. Characteristics of self-extinguishing Aames in $\mathrm{CH}_{4}$-air mixtures at $\mathrm{I}$ atm for various mole percent $\mathrm{CH}_{4}$ and spark ignition energies [112]. The " $\mathbf{x}$ " symbols denote extinction

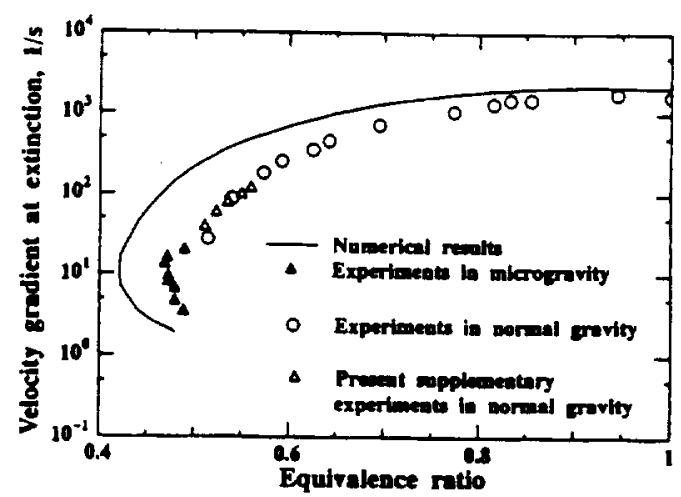

FiG. 3. Measured and predicted extinction strain rates for strained premixed $\mathrm{CH}_{4}$-air flames at $\mu \mathrm{g}$ [33] showing dual-limit behavior, that is, residence-time limited extinction at high strain rates (upper branch, "strong flames") and radiative loss extinction at low strain rates (lower branch, "weak flames")

reactions have high activation energies, small $T_{f}$ changes cause large changes in reaction rate and thus $S_{\mathrm{L}}$. An evolution equation for nonadiabatic expanding spherical flames is given by [28]:

$$
\frac{d S}{d R}+S^{2} \ln S^{2}=\frac{2 S}{R}-Q
$$

where $S=\left(d r_{\mathrm{f}} / d t\right) /\left(S_{\mathrm{L}}\left(\rho_{\ddagger} / \rho_{\mathrm{f}}\right)\right), R=r_{\mathrm{f}} /(\beta \delta I(L e, \varepsilon))$, $I(L e, \varepsilon)$ is a scaling function $(I>0$ for Le $<1$ and $I<0$ for $L e>1)$ and $Q=\left\{\beta \Lambda\left(T_{\mathrm{f}}\right) \delta^{2}\right\} /\left\{\lambda\left(T_{\mathrm{f}}-T_{\mathrm{x}}\right)\right\}$. The terms in equation 6 represent unsteadiness, heat release, curvature-induced stretch, and heat loss, respectively. For steady planar flames, equation 6 becomes $S^{2} \ln S^{2}=-Q$, which exhibits a maximum $Q=1 / e=0.3678 \ldots$ at $S=e^{-1 / 2}$, which corresponds to $S_{\mathrm{L}, \mathrm{im}}$ from equation 4. For Le $<1$, the curvature effect $(2 S / R)$ opposes heat loss $(Q)$, allowing mixtures that are nonflammable as plane Alames $(Q>1 / e)$ to exhibit expanding spherical flames until $r_{i}$ grows too large and thus the cunature benefit too small. For mixtures just outside the limit, the extinction radius may be very large. Such behavior, termed self-extinguishing flames (SEFs), is observed experimentally $[19,22]$ (Fig. 2) at $\mu g$ in nearlimit mixtures with Le slightly less than unity. (Mixtures with lower Le exhibit diffusive-thermal instabilities or flame balls discussed below.) Equation 6 also predicts, consistent with experimental observations [29], that SEFs cannot occur for Le $>1$ (thus, $R<0$ ) because both curvature and heat loss weaken the flame

Two experimental observations not predicted by equation 6 are that narrow mixture ranges exhibit both SEFs and normal flames and that the energy release before extinguishment can be orders of mag nitude greater than the ignition energy. Such behavior is predicted by computations [30] not subject to scaling limitations of activation energy asymptotics used to derive equation 6 . These calculations also show that for small initial $r_{f}$, all mixtures exhibit extinguishment, corresponding to nonignition behavior [31]. Thus, in mixtures exhibiting SEFs, flames extinguish at large curvature (small $r_{f}$ ) due to large $\Sigma$ and at small curvature due to radiative losses. This dual-limit behavior is also exhibited by many other types of flames described later.

Flames in hydrodynamic strain induced by counterflowing round jets are frequently employed to model turbulence-induced flame stretch effects. At steady state, the flame resides at the axial location $(y)$ where the axial velocity $\left(U_{y}\right)$ equals $S_{L}$ for the given $\Sigma=d U_{y} / d y$. As $\Sigma$ increases, $U_{y}$ increases, thus the flame moves toward the stagnation plane (smaller $y$ ) and the burned gas volume (thus radiative loss) decreases. As with curvature-induced stretch, for Le less than/greater than unity, moderate hydrodynamic strain increases/decreases $S_{\mathrm{L}}$, but for all $L e$, large strain extinguishes the flame [32]. Consequently, $\mu \mathrm{g}$ experiments [33] in low-Le mixtures (Fig. 3) reveal extinction behavior analogous to spherical flames. For large $\Sigma$, the short residence time $\left(\sim \Sigma^{-1}\right)$ causes extinguishment $\left(\Sigma^{-1} \approx t_{\text {chein }}\right)$ along the "normal flame" branch, analogous to nonignition behavior of spherical flames. In contrast, for low $\Sigma$, the residence time and burned gas volume are large; thus, radiative loss is significant $\left(t_{\text {rad }} \approx\right.$ $\left.t_{c h e m}\right)$, so radiative loss extinguishes the flame along the "weak flame" branch, analogous to SEFs. The optimal $\Sigma\left(\sim 13 s^{-1}\right)$ producing the minimum flammable fuel concentration corresponds to $\Sigma^{-1}=$ $0.08 \mathrm{~s}$, which is less than $t_{\text {vis }}$ or $t_{\text {invi }}$ thus, the $C$ shaped response and the entire weak-flame branch cannot be observed at $\mathrm{lg}$. The optimal $\Sigma$ is nearly the same for model and experiment, indicating that loss rates are modeled well, but the computed limit 


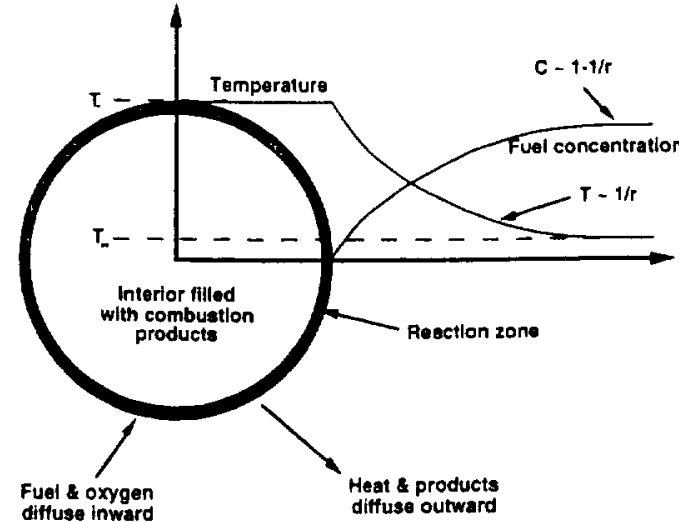

FIC. 4. Schematic diagram of a fame ball, illustrated for the case of fuel-limited combustion at the reaction zone The oxygen profile is similar to the fuel profile except its concentration is nonzero in the interior of the ball. The combustion product profile is identical to the temperature profile except for a scale factor.

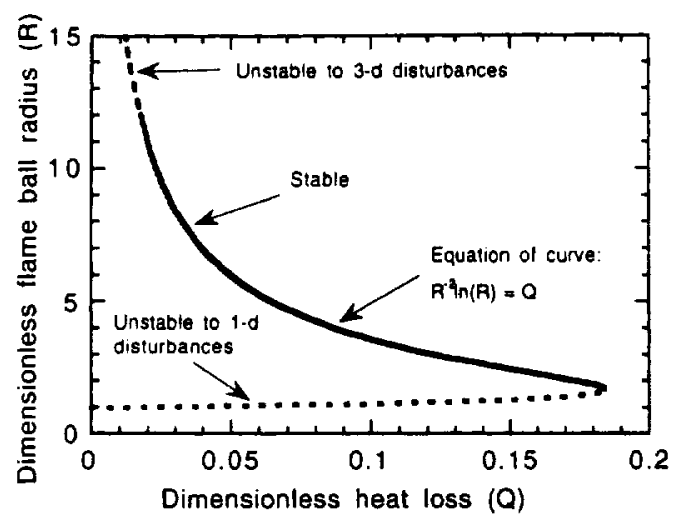

FIG. 5. Predicted effect of heat loss on flame-ball radius and stability properties [42] showing radially unstable (small) fame-ball solution, radially stable (large) flame-ball solution, and three-dimensional instability for large flame balls.

composition is leaner than the experimental limit, suggesting that the chemical mechanism used is inaccurate for weak mixtures. Due to the radiant loss decrease at moderate $\Sigma$, the flammability limit extension also occurs for $L e>1$, though, for sufficiently high $L e$, no $\mathrm{C}$-shaped response or flammability limit extension occurs [34]. (For spherically expanding flames, no flammability extension occurs for $L e>1$ because in this case there is no mechanism to reduce radiative loss by flame stretch.)

The combination of nonmonotonic response to $\Sigma$ plus the reduced radiative loss at larger $\Sigma$ causes several new extinction branches depending on $t_{\text {din.m. }}, t_{\text {ridd }}, \Sigma^{-1}$, and $L e[34,35]$. It is uncertain whether these branches are physically obsenable because they have not been identified experimentally and stability analyses have not been performed.

\section{Flame Balls}

Over 50 years ago. Zeldorich [36] showed that the steady mass, energy, and species consen ation equations admit solutions corresponding to stationary spherical flames, characterized by a flame radius $\left(r_{f}\right)$. Fuel and oxygen diffuse from the ambient mixture inward to the reaction zone while heat and combustion products diffuse outward (Fig. 4). Mass conservation requires that the Buid velocity be zero everywhere. The temperature and species mass fraction profiles have the form $c_{1}+c_{2} / r$, where $c_{1}$ and $c_{\text {, are }}$ constants. Corresponding solutions in planar and $c y-$ lindrical geometry cannot exist because the solution forms $c_{1}+c_{2} r$ and $c_{1}+c_{2} \ln (r)$, respectively, are unbounded as $r \rightarrow \infty$. Zeldovich [36] and others $[37,38]$ also showed that flame-ball solutions are $u n$ stable and thus probably not physically observable, although these solutions are related to flame ignition [37].

Forty years after Zeldovich [36], apparently stable flame balls were accidentally discovered in droptower experiments using $\mathrm{H}_{2}$-air mixtures [39] and aircraft-based $\mu \mathrm{g}$ experiments using various low-Le mixtures [40]. The $\mu \mathrm{g}$ environment facilitated spherical symmetry and prevented buoyancy-induced extinction. For mixtures sufficiently far from flammability limits, expanding spherical fronts composed of many individual cells were observed, whereas for more dilute mixtures, cells that formed initially did not split and instead closed up on themselves to form flame balls. (For still more dilute mixtures all flames eventually extinguished.) It was inferred that flame balls can occur in all near-limit low-Le mixtures; however, the short duration of drop-tower experiments and substantial $g$ fluctuations in the aircraftbased $\mu g$ experiments precluded definite conclusions. Recent space shuttle experiments [41] confirmed that flame balls can exist for at least 500 seconds (the entire experiment duration.)

Zeldovich [36] noted that radiative losses might stabilize flame balls; consequently, after their experimental observation, radiative loss effects on flame balls were analyzed [42]. For moderate loss, two solutions branches are predicted (Fig. 5), a strongly nonadiabatic large-radius branch and a nearly-adiabatic small-radius branch. For sufficiently strong losses, no solutions exist, indicating extinction limits. Stability analyses [42] predict that all small flames are unstable to radial disturbances, and large flames with weak loss (far from flammability limits) are unstable to three-dimensional disturbances. Close to extinction limits, the large-radius branch is stable to both disturbances. These predictions are consistent 


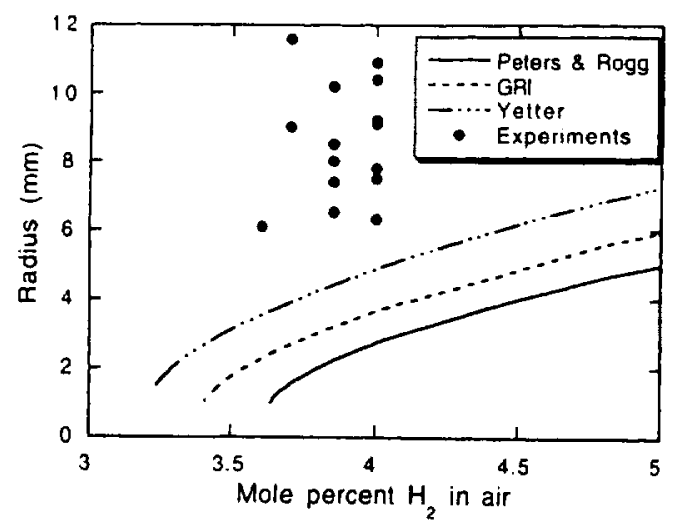

Fig. 6. Comparison of computed flame-ball radii as a function of $\mathrm{H}_{2}$ mole fraction in $\mathrm{H}_{2}$-air mixtures for three different $\mathrm{H}_{2}-\mathrm{O}_{2}$ chemical mechanisms, along with preliminary results from the STS-8.3 and STS-94 space experments [45].

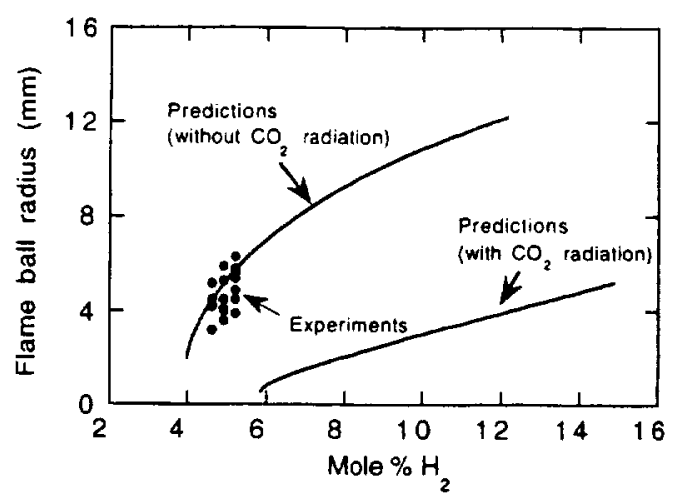

FIG. 7. Computed flame-ball radii as a function of the $\mathrm{H}_{2}$ mole fraction for steady flame balls in $\mathrm{H}_{2}-\mathrm{O}_{2}-\mathrm{CO}_{2}$ mixtures with $\mathrm{H}_{2}: \mathrm{O}_{2}=1: 2$, for optically thin $\mathrm{CO}_{2}$ radiation and with $\mathrm{CO}_{2}$ radiation artificially suppressed (optically thick limit for $\mathrm{CO}_{2}$ radiation). Preliminary experimental results from the STS-94 mission are also shown (filled circles) [45].

with the observed splitting cellular fames away from limits and stable balls close to limits. For Le close to or larger than unity, all flame balls are unstable for any loss magnitude [43], explaining why they are never observed in (for example) $\mathrm{CH}_{4}$-air mixtures (Le $\approx 0.9$ ) or $\mathrm{C}_{3} \mathrm{H}_{9}$-air mixtures ( $L e \approx 1.7$ ).

Numerical predictions of non-adiabatic flame balls employing detailed chemistry, diffusion, and radiation models $[44,45]$ are qualitatively consistent with these experimental and theoretical results. Still, quantitative agreement has been elusive (Fig. 6) for at least two reasons. First, flame-ball properties are very sensitive to the three-body recombination step
$\mathrm{H}+\mathrm{O}_{2}+\mathrm{H}_{2} \mathrm{O} \rightarrow \mathrm{HO}_{3}+\mathrm{H}_{2} \mathrm{O}[4.5]$ whose rate varies widely between different published $\mathrm{H}_{2}-\mathrm{O}_{2}$ reaction mechanisms. The second reason is reabsorption of emitted radiation in mixtures diluted with radiatively active $\mathrm{CO}_{2}$ or $\mathrm{SF}_{6}$. An upper bound on self-absorption of diluent radiation $\left(a_{p} \rightarrow x\right)$ is assessed by neglecting diluent radiation entirely because as $a_{\mathrm{p}} \rightarrow \infty$, radiative loss from the diluent vanishes and no additional heat transport occurs due to radiation. Agreement between predicted and measured flame radii is much better in this case (Fig. 7). strongly suggesting radiation modeling including reabsorption is needed for accurate predictions in these cases.

A key difference between propagating flames and flame balls is that propagating flames have convective-diffusive zones where temperature and concentration approach their ambient values in proportion to $e^{-r / s}$. whereas flame balls have purely diffusive zones where the approach is proportional to $\mathrm{L} / r$. Plane flames respond on short time scales $t_{\text {chum }}=$ $\delta^{2} / \alpha$, whereas the gradual $1 / r$ flame-ball profiles produce properties dominated by the far-field length scale $\beta r_{r}$, and thus diffusion time scales $\left(\beta r_{f}\right)^{2 / \alpha}[42]$, typically $100 \mathrm{~s}$. These scales are relevant to stability and extinction limits because they affect the times for radiant combustion products to diffuse to the farfield and indicate large volumes of gas $\left(\sim \beta^{3} r^{3}\right)$ where radiative loss affects flame balls. Such large scales are confirmed by space experiments $[41]$ and numerical simulations $[44,4,5]$. Droplet and candle flames (discussed later), which have quasi-spherical, diffusion-dominated far-fields, exhibit analogous behavior.

\section{Gaseous Non-Premixed Flames}

\section{Stretched Flames}

Non-premixed flames, where fuel and oxidant are separated before combustion, are affected by stretch differently than are premixed Glames. The most significant difference is that the flame position is determined by the location of stoichiometric mixture fraction, dictated by mixing considerations, rather than being determined by balances between $S_{\mathrm{L}}$ and $U$ as in premixed Hames. Consequently, non-premixed flames have considerably less freedom of movement. Also, premixed flames have characteristic thicknesses $\delta \sim \alpha / S_{\mathrm{L}}$ unrelated to the flow environment, whereas non-premixed flames have only the diffusion length scale $\delta \sim(\alpha / \Sigma)^{1 / 2}$. With fixed flame location and $\delta$ increasing monotonically with decreasing $\Sigma$, non-premixed flames with radiative loss exhibit only simple C-shaped responses to strain (Fig. 8) [46], with a short residence time extinction branch $\left(t_{\text {chem }}>\Sigma^{-1}\right)$ and a radiative loss extinction

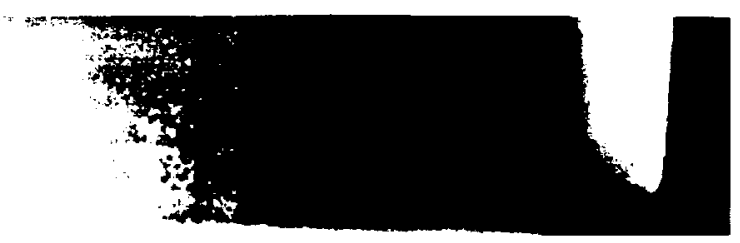




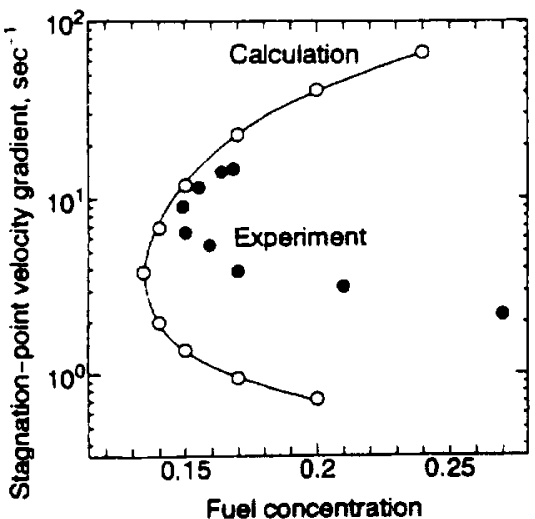

FIG \$. Measured and predicted extinction strain rates for strained non-premixed $\mathrm{N}_{2}$-diluted $\mathrm{CH}_{4}$ versus air counterflow flames at $\mu \mathrm{g}[46]$ showing dual-limit response analogous to premixed flames (Fig. 3).

TABLE ?

Predicted scalings of flame heights $\left(L_{i}\right)$ and residence times $\left(t_{\text {jet }}\right)$ for non-premixed round-jet and slot-jet flames under momentum-dominated and buoyancydominated conditions

\begin{tabular}{|c|c|c|c|}
\hline Geometry & $\begin{array}{c}\text { Flow } \\
\text { Mechanism }\end{array}$ & $L_{f}$ & $\mathbf{t}_{\text {jet }}$ \\
\hline Round-jet & Momentum & $U_{1}^{*} d_{i j}^{2} / D$ & $d_{0}^{2} / D$ \\
\hline Round-jet & Buoyant & $U_{1}, d_{d ;}^{2} / D$ & $\left(U_{0} d d_{0 / g D}^{2 / g}\right)^{1 / 2}$ \\
\hline Slot-jet & Momentum & $U_{1} d_{i \gamma}^{2} D$ & $d_{0}^{2} / D$ \\
\hline Slot-jet & Buoyant & $\left(C_{0}^{4} d_{0}^{4} / D^{2} g\right)^{1 / 3}$ & $\left(U_{0}^{n} d_{0}^{2} g^{2} D\right)^{1 / 3}$ \\
\hline
\end{tabular}

branch $\left(t_{\text {rad }}<\Sigma^{-1}\right)$ rather than the complicated responses found for premixed flames [34]. The only significant difference in flame structures near the two limits is $\delta$ [46], a situation quite unlike premixed flames.

For the radiative extinction branch $t_{\text {chein }}$ is still a factor because $t_{\text {rad }} \approx \Sigma^{-1}$ results in order unity decreases in flame temperature, thus causing exponentially large decreases in $t_{\text {chem }}$. Even conditions far from extinction at $1 g$, therefore, may exhibit radiative extinction at $\mu \mathrm{g}$ due to much larger residence times. This mechanism also applies to radiative extinction of other types of non-premixed flames discussed later. It is also somewhat analogous to the lower branch of strained premixed flames (Fig. 3) and the large-radius branch of flame balls (Fig. 5).

The experiments shown in Fig. 8 suggests that no flames exist below some value of $\Sigma$, whereas the model predicts flames at arbitrarily low $\Sigma$. Similar behavior was seen for premixed flames (Fig. 3). This suggests an additional loss mechanism not considered by the model, probably axal conductive heat losses to the jets or radial conductive loss to inert gases surrounding the reactant streams. This would induce $t_{\text {cink } 1}^{-1} \approx 2.9 \mathrm{~s}^{-1}$ if $d$ is the jet spacing $(25 \mathrm{~mm}$ ).

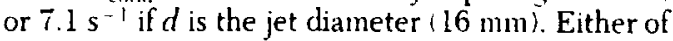
these are roughly consistent with the minimum $\Sigma$ in Fig. 8. Thus, apparatuses large enongh to study flames at $1 g$ without substantial conductive loss. where maximum length scales are about $\left(\alpha t_{17,}\right)^{1,2}$, are insufficient for the weaker flames attainable at $\mu \mathrm{g}$, where maximum length scales are about $\left(\alpha t_{\text {rial }}\right)^{1 ?}$ ?

\section{Laminar Gas-Jet Flames}

A fuel jet issuing into an oxidizing enrironment is one of the simplest types of flames. Jost [47] and Roper [48] estimated the flame height $\left(L_{\uparrow}\right)$ and residence time from jet exit to flame tip $\left(t_{\mathrm{jet}}\right)$ by determining the height $(y)$ where the transierse diffusion time $\left(d(y)^{2} / D\right.$, where $d(y)$ is the stream tube width) equals the convection time $\left(C^{\prime}(y) / y\right.$, where $C^{\prime}(y)$ is the axial velocity). When buoyancy and viscosity effects are negligible (momentum-controlled jets) $U(y)$ is constant and equals the jet exit velocity $\left(U_{n}\right)$ whereas when buoyancy effects dominate, $\mathcal{C}(y)$ $(g y)^{1 / 2}$. In either case, mass conservation requires that $d(y)^{2} U(y)=d_{0}^{2} U_{0}=$ constant for round jets or $d(y) U(y)=d_{0} U_{0}=$ constant for slot jets. The resulting estimated scalings for $L_{\mathrm{f}}$ and $t_{\mathrm{jet}}$ are given in Table 2 . Transition from buoyancy-controlled to momentum-controlled conditions occurs when the time scale for the former exceeds the latter, which corresponds to $U_{\mathrm{o}}>g d_{\sigma}^{2} / D$ for either round jets or slot jets. The scalings for momentum-dominated Hames presume constant $U$, which is reasonable for collowing Burke-Schumann Aames, but for nonbuoyant jet flames without coflow, the jet spreads and decelerates. For this situation [49]

$$
\begin{gathered}
L_{\mathrm{f}}=\frac{U_{\mathrm{o}} d_{0}^{2}}{D} \frac{1}{2 S c^{1 / 2}} \sqrt{\ln \left(\frac{1}{1-c_{\mathrm{s}}}\right)} \Rightarrow \\
t_{\mathrm{jet}}=\int_{0}^{L_{\mathrm{f}}} \frac{d y}{U(y)}=\frac{d_{\mathrm{o}}^{2}}{D} \ln \left(\frac{1}{1-c_{\mathrm{s}}}\right)
\end{gathered}
$$

Because $S c \approx 1$, the scalings of $L_{\mathrm{f}}$ and $t_{\text {jet }}$ are similar with or without viscosity. Fig. 9 shows measurements of $L_{\mathrm{f}}$ for $\mathrm{CH}_{4}$ flames [50]. Note that, as the scalings predict, $L_{\mathrm{f}} / d_{\mathrm{o}} \sim R e \equiv U_{0} d_{i} / v$ at both $\mathrm{lg}$ and $\mu \mathrm{g}$, and only small differences exist between $\mathrm{lg}$ and $\mu \mathrm{g}$ flame lengths.

All $\mu \mathrm{g}$ studies show larger flame widths $(w)$ at $\mu \mathrm{g}$ than $\lg$ due to lower $U$ and longer $t_{\text {jet }}$ [50]. Also, $w$ is larger at $\mu \mathrm{g}$ because the temperatures are lower (see below) and $D \sim T^{1-5}$. Because $w$ depends on whether $U$ is accelerating (buoyant jets), constant (nonbuoyant Burke-Schumann Alames), or decelerating (nonbuoyant jets), $w$ is more difficult to predict than is $L_{\mathrm{f}}[2]$. The difference between $\mathrm{lg}$ and $\mu \mathrm{g}$ widths decreases as Re (thus, $U_{0}$ ) increases (Fig. 10). The nonbuoyant widths increase slightly with $R e$, 


$$
\text { , } \quad
$$




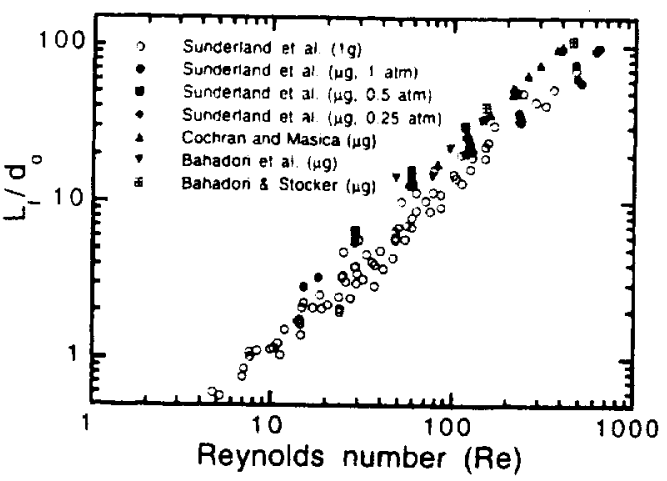

Fic. 9. Measured flame lengths, normalized by jet diameter. as a function of the jet Reynolds number for nonpremixed $\mathrm{CH}_{4}$-air jet flames at $\mathrm{lg}$ and $\mu \mathrm{g}$. Data is taken from a variety of sources and compiled in Ref. [50]. The data show a nearly linear relationship between fiume length and Remolds number, with generally longer flame lengths at $\mu \mathrm{g}$, due to the differences between residence times under buovancy-driven versus momentum-driven residence times.

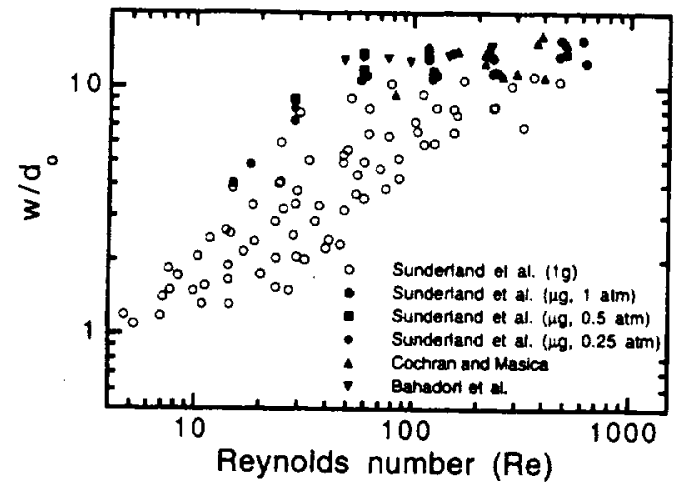

FIG. 10. Measured fame widths, normalized by jet diameter, as a function of the jet Reynolds number for nonpremixed $\mathrm{CH}_{4}$-air jet flames at $\mathrm{lg}$ and $\mu \mathrm{g}$. Data is taken from a variety of sources and compiled in Ref. [50]. The data show larger flame widths at $\mu \mathrm{g}$ due to the differences between accelerating flow at $\mathrm{Ig}$ versus decelerating flow at $\mu \mathrm{g}$. The data also show that, consistent with theoretical predictions, the width is nearly independent of Reynolds number for nonbuoyant conditions, except at low $R e$ where boundary-layer approximations are invalid.

whereas all aforementioned models predict selfsimilar flame shapes with no effect of Re. This may be due to axial diffusion, not considered in these models, which increases mixing over that with radial diffusion alone. This suggestion is supported by the results shown in Fig. 10 which show that $w / d_{0}$ is lowest for lowest $R e(\approx 20)$, where axial diffusion is

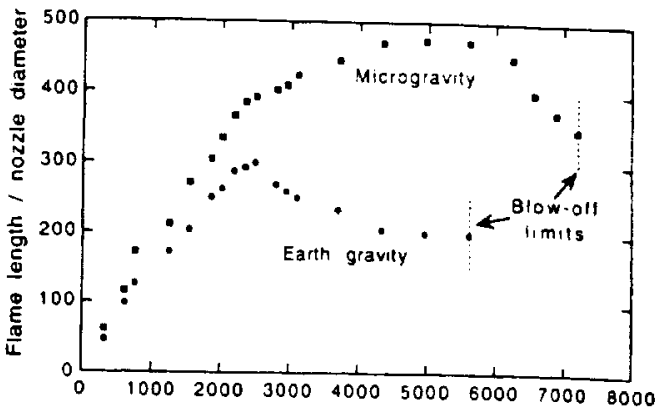

FIG. 11. Measured thame heights for non-premixed $\mathrm{C}_{3} \mathrm{H}_{4}$-air jet Hames at $\mathrm{lg}$ and $\mu \mathrm{g}\{51\}$ showing transition to turbulence. Note $\lg$ flame lengths are shorter than $\mu g$ flame lengths, even at very high Reynolds numbers.

most significant, but asymptotes to fixed values at high Re.

Compared to yellow $\mathrm{lg}$ flames, $\mu \mathrm{g}$ gas-jet flames are more red $[49,50]$, indicating lower blackbody soot temperatures and presumably lower maximum flame temperatures. This occurs because $t_{\text {ite }}$ is larger at $\mu \mathrm{g}$ and thus radiative loss effects $\left(\sim t_{\mathrm{k}} \cdot \mathrm{t} t_{\mathrm{rud}}\right)$ are greater. Drop-tower [51] and space [.52] experiments indicate surprisingly large and consistent radiative loss fractions $(0.45-0.60)$ at $\mu \mathrm{g}$ compared to $0.07-$ 0.09 at $\mathrm{lg}$, for various fuels, pressures, $\mathrm{O}$, mole fractions, and flow rates. Thus, differences in $t_{j \mathrm{jet}}$ at $\mathrm{Ig}$ and $\mu g$ result in widely varying characteristics even for flames having nearly the same $L_{f}$.

\section{Turbulent Flames}

In turbulent non-premixed jet flames, $D$ is not fixed but rather is nearly proportional to $u^{\prime} L_{1}$. Because $u^{\prime} \sim U_{\mathrm{o}}$ and $L_{\mathrm{I}} \sim d_{\mathrm{o}}, L_{\mathrm{f}} \sim U_{\mathrm{d}} d_{d}^{2} \mathrm{u}^{\prime} L_{\mathrm{I}} \sim d_{\mathrm{o}}$ for round jets; thus, $L_{\mathrm{f}}$ is independent of $U_{0}$. This prediction is supported by classical $1 g$ experiments [53] as well as recent $\mu \mathrm{g}$ experiments [54] (Fig. 11). Note that $L_{\mathrm{f}}(\mu \mathrm{g}) / L_{\mathrm{f}}(\mathrm{Ig})$ is practically constant even beyond the transition to turbulent conditions (high $U_{0}$ and $R e$ ). Note also that the maximum $R e$ at which flame exists (the "blow-off" limit) is different at $1 g$ and $\mu g$. This is surprising because blow-off conditions are typically controlled by behavior near the flame base [55], where buoyancy effects are often considered insignificant. This suggests that blow-off is partially affected by convection induced by the buoyant plume far above the jet exit, even at very high $U_{0}$. One would intuitively conclude that the $1 g$ flames should blow-off at lower $U_{0}$ because buoyant flow would induce higher "effective" $U_{1,}$, which is consistent with Fig. 11. This shows that buoyancy effects are quite ubiquitous even under conditions commonly thought to be unaffected by buovancy. 

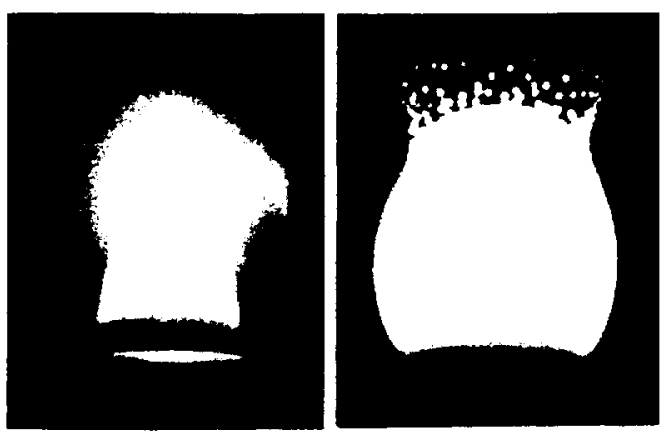

FIG. 12. Direct photographs of sooting $\mathrm{n}_{-} \mathrm{C}_{4} \mathrm{H}_{10}$ nonpremixed gas-jet flames at $\lg$ (left) and $\mu g$ (right) at $R e-$ 42. jet diameter $10 \mathrm{~mm}$, showing etidence of thermophoresis-induced agglomeration at $\mu \mathrm{g}$. Photographs courtesy of Professor O. Fujita.

\section{Soot Formation Processes}

Compared with $\mathrm{Ig}$ flames $\mu \mathrm{g}$ gas-jet flames have much greater tendencies to emit soot $[49,56]$, indicating that increases in $t_{\mathrm{jet}}$ (thus, greater time for soot formation) plus broader regions in which composition and temperature are favorable for soot formation $[56,5 \%]$ outweigh lower temperatures at $\mu \mathrm{g}$, which decreases soot formation [58]. Recent quantitative measurements [56] show peak soot-volume fractions about twice as high at $\mu \mathrm{g}$ than $\mathrm{lg}$ for $50 \%$ $\mathrm{C}_{2} \mathrm{H}_{2} / 50 \% \mathrm{~N}_{2}$-air flames.

Surprisingly, $\mu \mathrm{g}$ gas-jet flames exhibit "smoke points," corresponding to critical $U_{0}$, below which soot is consumed within the flame, and above which soot is emitted from the flame [57]. Smoke points are expected for buoyant round-jet flames because $t_{\text {jet }}-U_{o}^{1 / 2} ;$ thus, increasing $U_{o}$ increases the time available for soot formation. But for nonbuoyant flames, $t_{\mathrm{jet}} \sim U_{0}^{0}$, suggesting no smoke point should exist. Fully elliptic numerical computations [59] show that, for some circumstances, $t_{\mathrm{jet}}$ does increase monotonically with $U_{0}$, which could explain smoke points for nonbuoyant flames. This behavior was suggested to result from axial diffusion effects [59], but in this case, $t_{\text {jet }}$ should asymptote to constant values for large $L_{F}$, where axial diffusion is negligible. Thus, simple explanations of $\mu \mathrm{g}$ smoke points remain elusive. Residence-time considerations alone may be misleading; soot precursor temperature-composition-time history effects are apparently also important.

With weak convection, thermophoretic forces, which move particles toward lower temperatures, are an important effect. If convection and temperature gradients are in the same direction, the convective and thermophoretic forces may balance at some location. This leads to soot accumulation inside the flame front at $\mu \mathrm{g}$ (Fig. 12) [60], where an annulus of soot accumulation is convected bv axial flow through the flame tip. Downstream, for reasons not yet explained, the soot annulus fragments, creating crounlike structures. These effects are only obsenable at $\mu g$ where convection velocities are comparable to thermophoresis velocities, $(\approx 5 \mathrm{~mm} / \mathrm{s}$ for the conditions of Fig. $12[60])$.

\section{Condensed-Phase Combustion}

\section{Droplet Combustion}

The first microgravity combustion experiments were isolated fuel-droplet tests conducted by $\mathrm{Ku}$ magai and Isoda [61]. At $\mathrm{lg}$, experinental measurements of droplet buming rates are compromised by buoyant convection, which destroys the spherical symmetry and inducing additional heat and mass transport, which alters buming rates and complicates modeling. Classical theory $[62,63]$ predicts that buming rates for spherically symmetric buovancyfree droplet burning are given by

$$
\begin{aligned}
& d_{\mathrm{do}}^{2}-d_{\mathrm{d}}^{2}=K t \\
& K \equiv\left(8 \lambda \rho_{\mathrm{d}} C_{\mathrm{p}}\right) \ln (1+B)
\end{aligned}
$$

In experimental studies, the droplet diameter $d_{\mathrm{d}}$ could be fixed by forcing fuel through a porous sphere at rates that balances evaporation, leading to a steady mass burning rate $(m)=\langle\pi / 4) \rho_{\mathrm{p}} d_{\mathrm{d}} K$, but most experiments employ fuel droplets where $d_{t}$ decreases with time. Somewhat surprisingly, many fuel-droplet results follow equation 8 well despite unsteadiness, heat losses, soot formation, and water absorption effects discussed below.

As with flame balls, steady solutions exist for spherical droplet flames even in infinite domains, with the flame front located at

$$
d_{\mathrm{f}}=d_{\mathrm{d}} \ln (1+B) / \ln (1+f)
$$

Whereas flame balls are convection-free, droplet flames exhibit Stefan flow due to fuel vaporization at the droplet surface. Mass conservation dictates that the Stefan velocity decays as $1 / r^{2}$, causing temperature and concentration profiles to vary with radius in proportion to $(1+B)^{-d_{d} / 2 r}$ rather than $\mathrm{V} r$ as in Hame balls, although these profiles, when normalized by flame radius, are indistinguishable at large $r$. Unlike flame balls, heat losses are not required for stable droplet flames because the flame location cannot move away from the stoichiometric contour.

The characteristic time scale for droplet combustion is $t_{\text {drop }} \approx d_{f}^{2} / \alpha$. This leads to two extinction limits $[64,65]$, one for small $d_{\mathrm{f}}$ where $t_{\mathrm{drnp}}<t_{\text {chem }}$ and thus fuel and oxidant cannot react before interdiffusing, and one for large $d_{f}$ where $t_{\text {drop }}>t_{\text {rad }}$ and thus the temperature decrease from radiative loss 


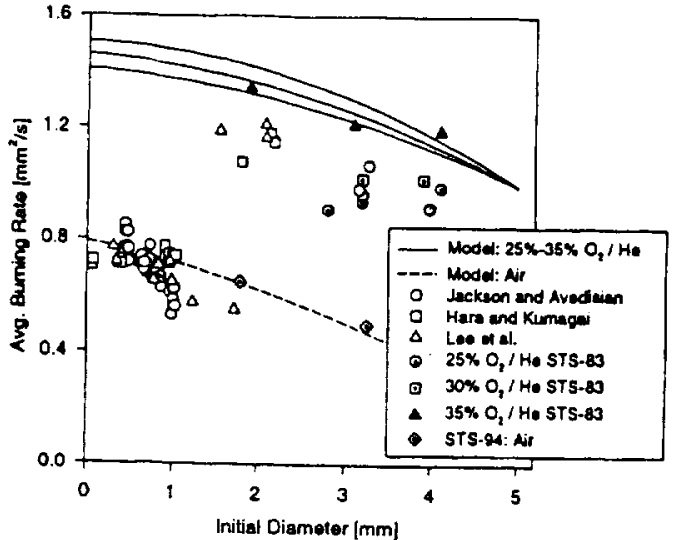

FIc. 13. Effect of initial droplet diameter $\left(d_{t_{1}}\right)$ on quasisteady burning rate $(K)$ for heptane droplets buming in air and an $\mathrm{O}_{2}-\mathrm{He}$ atmosphere at $\mu \mathrm{g}$, showing that $K$ decreases with increasing $d_{d}$, apparently because of increased accumulation of soot and gas-phase radiant species for larger $d_{\mathrm{do}}[70]$.

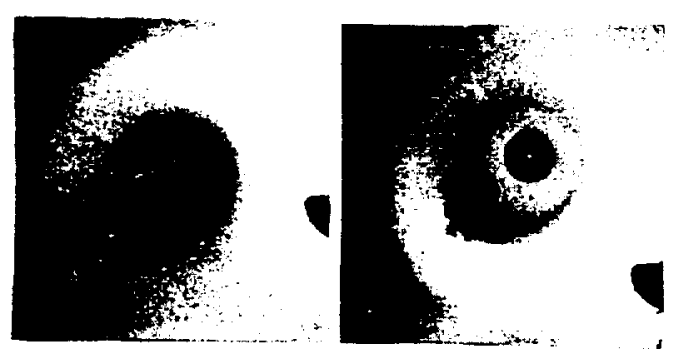

FIG. 14. Direct photographs of heptane droplets burning in air at $\mu \mathrm{g}$ showing spherically symmetric combustion (left) and a soot "tail" formed by weak convection effects (right) [68]. Photographs courtesy of Professor T. Avedisian.

reduces the reaction rate sufficiently to cause extinction. The former occurs when $d_{f}<\left(\alpha t_{\text {chem }}\right)^{1 / 2}$ and the latter when $d_{f}>\left(\alpha t_{\text {rad }}\right)^{1 / 2}$. Recent space experiments have reported radiative extinction of large droplets in air [66] and $\mathrm{O}_{2}-\mathrm{He}$ [67] atmospheres. Even when radiation does not cause extinguishment, it causes a decrease in $K$, especially when soot formation is significant $[68,69]$.

In experiments, $K$ is not constant as the quasisteady model (equation 8 ) predicts, but rather decreases with increasing $d_{d o}$ (Fig. 13) [70]. This suggests that nonsteady effects, specifically the diffusion of thermal energy and radiant combustion products into the far field, may be significant; this would cause changing radiative loss over time. Analogous behavior occurs in flame balls [41], where radiative loss requires $\sim 100 \mathrm{~s}$ to reach steady state even in flame balls much smaller than typical droplet flames. Another indication of unsteadiness in droplet flames is that constant $d_{f} / d_{\mathrm{a}}$ values are not generally achieved. especially for large droplets at $\mu g[69,70]$, in contrast to the predictions of the quasi-steady theory. Unsteadiness effects in droplet Hames were recently analyzed by King [71]. The effect of $d_{\mathrm{t}, 3}$ on $K$ has also been proposed [68] to result from soot accumulation, which is more significant for larger $d_{1,1}$, and acts to decrease net heat release and increase radiation.

As with non-premixed gas-jet flames, soot particles in $\mu g$ droplet flames exhibit thermophoresis effects $[72,73]$, leading to soot agglomeration between the droplet and flame front (Fig. 14). The agglomerates may break apart suddenly, leading to multiple burning fragments. Because velocity and temperature gradients are readily modeled in spherical droplet flames, such experimental observations enable assessment of thermophoresis effects on suot particle transport.

Another complicating factor arises in fuels that are miscible in water. The fuel may absorb water vapor from the combustion products, causing significant departure from equation 8 and reducing Hammability. Such behavior is found $[74,75]$ in methanol flames, where extinction diameters depend substantially on $d_{\mathrm{da}}$ due to water absorption during combustion.

Finally, in recent space experiments, flame oscillations with amplitudes comparable to the mean flame diameter have been observed [76]. The oscillation amplitude grew with time with extinction typically occurring after eight cycles. The oscillation frequency was approximately $1 \mathrm{~Hz}$. Cheatham and Matalon [65] predicted oscillations of roughly the correct frequency in droplet flames of pure fuels under near-extinction conditions when the reactant Lewis numbers are sufficiently high. To date, oscillations have been reported for methanol/dodecanol (80/20 mass fraction) bicomponent droplets burning in air; it is uncertain whether oscillations also occur in pure fuels. Moreover, $\mu \mathrm{g}$ experiments in $\mathrm{O}_{g}-\mathrm{He}$ atmospheres [67], with much higher Le, did not exhibit oscillations. One possible explanation is that droplet support fibers were used in Ref. [76] but not Ref. [67]. The fiber could increase conductive and radiative losses, which encourage oscillations [65]. Another explanation is that, because oscillations occur only near extinction conditions, depletion of oxygen (leading to extinction) was much more significant in the smaller combustion chamber used in the methanol/dodecanol experiments. Such oscillatory instabilities are discussed further in the following section.

\section{Candle Flames}

An excellent example of the differences between $\mathrm{lg}$ and $\mu \mathrm{g}$ flames is seen in perhaps the most common and familiar of all combustion processes - candle flames. At $1 \mathrm{~g}$, candle flames are supported by air 
- 

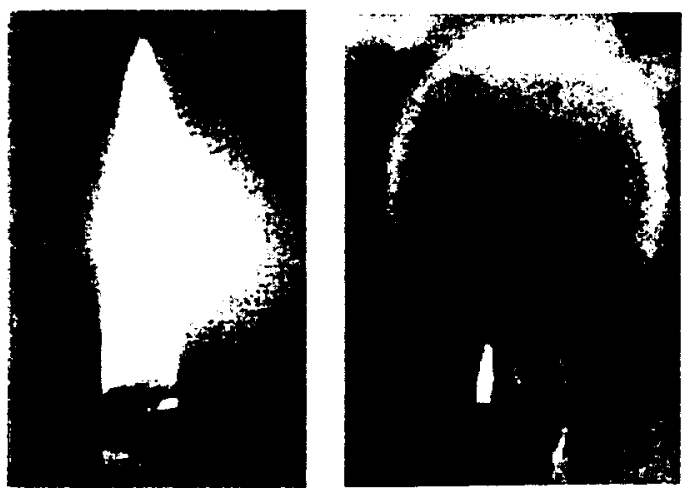

Fic. 15. Direct photographs of candle Hames at $\lg$ and $\mu g$, showing impact of buovant flow on Aame shape [77].

entrained via buoyant flow, which generates a selfsustaining flame and flow configuration. Obriously, this mechanism cannot apply at $\mu \mathrm{g}$. The spherical diffusion equation admits steady solutions for flame balls and droplet flames without forced convection. An interesting question is whether candle flames, which are not strictly spherical, can behave similarly. Space experiments $[77,78]$ indicate that candle flames can be steady for $>45 \mathrm{~min}$, with flame shapes typically hemispherical (Fig. 15). Eventually, the flames always extinguished, whereas the spherical flame model predicts that the flame would burn indefinitely. Protective screens used in the experiments may have limited the $\mathrm{O}_{2}$ supply, eventually allowing sufficient $\mathrm{O}_{2}$ depletion to cause extinguishment.

Before extinction, the candle-flame edge frequently advanced and retreated periodically. The oscillation amplitude increased over time, and on one retreating cycle, the entire flame extinguished. With larger wicks (thus, larger flame diameters), oscillations started spontaneously, whereas with smaller wicks, oscillations occurred only when solid objects were placed near the flame. Only a few cycles before extinction were observed in the Spacelab experiments [77], whereas hundreds of cycles were observed in the Mir experiments [78]. This is probably because the protective screen was much more permeable in the Mir experiments, thereby decreasing the $\mathrm{O}_{2}$ depletion rate and maintaining the flame at near-extinction conditions much longer.

At least two possible explanations for these oscillations have been advanced. Cheatham and Matalon [6.5] showed that, near extinction, oscillatory instabilities occur in spherically symmetric droplet flames with radiative loss at sufficiently high Lewis numbers. Their predicted oscillation frequencies $(0.7-$ $1.4 \mathrm{~Hz}$ ) are comparable to experimental observations, however, the differences between spherically symmetric droplet flames and roughly hemispherical candle flames were noted [65]. Altematively, Buckmaster [79] showed that the flame "edge" separating burning and nonburning regions of non-premixed flames exhibit oscillator behavior at (for quasi-stationary edges) $L e>1+S / \beta\left(1-\left(T / T_{1}\right)\right) \approx 2$ when $L e$ for the other reactant is unity. $L_{e} \approx 1$ for $\mathrm{O}_{2}$ in $\mathrm{N}_{2}$, but $L e$ for fuel vapors is probably closer to 2 ; thus, edge-flame instabilities could explain the observed oscillations. While neither instabilitv mechanism has been definitively linked to the candle-flame experiments, both predict greater propensities for oscillation with greater heat losses, which is consistent with the observation that oscillations occur near extinction.

\section{Flame Spread over Solid Fuel Beds}

Flame spread over solid fuel beds is typically classified as opposed-flow, where convection opposes Hame propagation, or concurrent-flow. Because upward buoyant flow opposes flame spread, lg downward flame spread is opposed-flow, whereas upward flame spread is concurrent-How. At $\mu \mathrm{g}$ without forced flow, flame spread is always opposed-flow because the flame spreads toward the fresh oxidant with a self-induced velocity equal to the spread rate $\left(S_{f}\right)$. At $l g$, self-induced convection is negligible because buoyancy-induced flows are typically $\left(g \alpha_{o}\right)^{1 / 3}$ $\approx 0.10 \mathrm{~m} / \mathrm{s} \gg S_{f}$. Very few concurrent-flow flame spread have been conducted at $\mu \mathrm{g}[80]$, consequently, this section focuses on opposed-flow spread.

$S_{f}$ is estimated by equating the conductive heat flux to the fuel bed $\left(=\lambda(\delta W)\left(T_{f}-T_{v}\right) / \delta\right.$, where $\delta=\alpha / U$ is the thermal transport zone thickness and $U$ is the opposed-flow velocity (forced, buoyant and or self-induced), to rate of fuel bed enthalpy increase $\left(=\rho_{s} C_{P, s} \tau_{s}\left(T_{v}-T_{x}\right) W S_{f}\right)$. Assuming mixing-limited reaction (infinite-rate chemistry), for thermally thin fuels, where heat conduction through the solid is negligible, $S_{f}$ is predicted to be $[81,82]$

$$
S_{\mathrm{f}}=\frac{\pi}{4} \frac{\grave{\lambda}_{\mathrm{g}}}{\rho_{\mathrm{s}} C_{\mathrm{p}, \mathrm{s}} \tau_{\mathrm{s}}} \frac{T_{\mathrm{f}}-T_{\mathrm{v}}}{T_{\mathrm{v}}-T_{\mathrm{x}}}
$$

Note that $S_{f}$ is independent of $U$ and $P$. For thermally thick fuels, where heat conduction through the solid fuel dominates, $\tau_{\mathrm{s}}$ is the thermal penetration depth into the solid, estimated by equating the conductive heat flux to the fuel bed to the heat flux through the fuel $\left(=\lambda_{s v}(\delta W)\left(\left(T_{v}-T_{x}\right) / \tau_{s}\right)\right.$, where the subscript $y$ refers to the direction normal to the fuel surface). This leads to the exact solution [81]

$$
\begin{gathered}
\tau_{\mathrm{s}}=\frac{\lambda_{\mathrm{s}}\left(T_{\mathrm{v}}-T_{\mathrm{x}}\right)}{\lambda\left(T_{\mathrm{f}}-T_{\mathrm{v}}\right) / \delta}=\frac{\lambda_{\mathrm{s}}\left(T_{\mathrm{v}}-T_{\mathrm{x}}\right)}{\lambda\left(T_{\mathrm{f}}-T_{\mathrm{v}}\right)} \frac{\alpha}{S_{\mathrm{f}}} \\
\Rightarrow S_{\mathrm{f}}=U \frac{\lambda \rho C_{p}}{\lambda_{\mathrm{s}}{\rho_{\mathrm{s}}, \mathrm{s}}_{(}}\left(\frac{T_{\mathrm{f}}-T_{\mathrm{v}}}{T_{\mathrm{v}}-T_{x}}\right)^{2}
\end{gathered}
$$

Note that, unlike the thin-fuel case, for thick fuels $S_{f} \sim U^{1} P^{1}$. 


$$
\text { ? }
$$




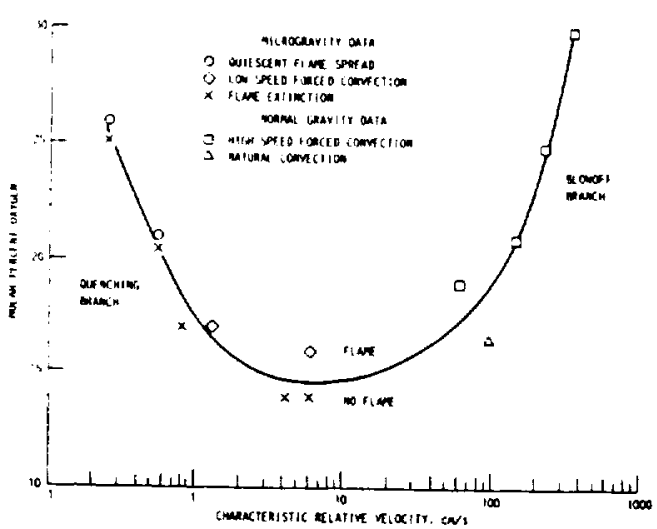

FIG. 16. Minimum mole percent $\mathrm{O}_{2}$ in $\mathrm{N}_{2}$ supporting flame spread over a thin solid fuel bed, as a function of the opposed flow velocity (U) [9:3], showing dual-limit behav. ior, that is, residence-time limited extinction at high $U$ and radiative loss extinction at low $U$.

Dual-limit extinction behavior is observed in $\mu \mathrm{g}$ flame-spread experiments (Fig. 16) [83]. The time for thermal energy to diffuse across the convectiondiffusion zone $\left(t_{\text {diff }}\right)$ is $\delta / U=\alpha / U^{2}$; thus, high- $U$ extinction occurs when $t_{\text {liff }}<t_{\text {chem }}$ or $U>$ $\left(\alpha / t_{\text {dhem }}\right)^{1 / 2}$ and radiative extinction occurs when $t_{\text {diff }}$ $>t_{\text {rad }}$ or $U<\left(\alpha / t_{\text {rad }}\right)^{1 / 2}$. (Surface radiative loss may also be important, particularly at moderate and higher $U[84]$.) Interestingly, the minimum $\mathrm{O}_{2}$ concentration supporting combustion $\left(\chi_{\mathrm{O} 2 \mathrm{lim}}\right)$, and thus the greatest hazard, corresponds to $U \approx 0.1 \mathrm{~m} / \mathrm{s}$, which is lower than buoyant convection at $1 \mathrm{~g}$, and might correspond to ventilation drafts in manned spacecraft.

A radiative loss parameter can be defined as $H \equiv$ $t_{\text {liff }} / t_{\text {rial }}=\alpha / C^{-1} t_{\text {rixl }}$. Because $H \sim L^{-2}-S_{f}$ is lower at $\mu \mathrm{g}$ where $E$ is lower and thus $H$ is higher. Experiments [55] (Fig. 17) show that an imposed forced How at $\mu g$ increases $S_{f}$ because $C^{\top}$ ( sum of forced flow and $S_{f}$ ) increases and thus $H$ decreases, whereas at higher $U$ (whether buovant or forced), $S_{f}$ decreases as the high- $U$ limit is approached. For $21 \% \mathrm{O}_{2}$ or lower, the infinite-rate chemistn: prediction of equation $9, S_{f}-L^{\prime \prime}$, is never achieved. Only at $30 \% \mathrm{O}$ is $T_{f}$ high enough that this condition is achieved

Because $\alpha-P^{-1}$ and $t_{\text {riad }} \sim P^{\prime}, H \sim P^{-1}$. thus for thin fuels, $S_{f}$ should increase with $P$ toward the ideal (adiabatic) value (equation 9). This is confirmed by quiescent thin-fuel space experiments $[56,87]$, which show $S_{f}$ increasing from 3.2 to $5.9 \mathrm{~mm} / \mathrm{s}$ as $P$ increases from 1.0 to $2.0 \mathrm{~atm}$ with fixed $\mathrm{O}_{2}$ mole fraction $(0.50)$. For these conditions, $H$ decreases from 24 to 3.5 , thus even at the highest $P$, radiative effects are probably still important. This is consistent with computations [86] that predict $S_{f}=12 \mathrm{~mm} / \mathrm{s}$ (almost independent of $P$ ) for adiabatic conditions for this fueVatmosphere combination.

Neither $\mathrm{N}_{2}$ nor $\mathrm{O}_{2}$ emit thermal radiation: thus, for flames in $\mathrm{O}_{2}-\mathrm{N}_{2}$ atmospheres, only $\mathrm{H}_{2} \mathrm{O}$ and $\mathrm{CO}_{2}$ combustion products radiate significantly. For these cases, typically $a_{\overline{\mathrm{p}}} \mathrm{I} \approx 1.2 \mathrm{~m} \gg \delta$ and thus, radiative transfer is optically thin inegligible reabsorption). When $a_{\mathrm{p}} \delta \geq 1$, reabsorption effects cannot be neglected. With reabsorption, some radiation is not lost and may augment conduction to increase $S_{f}$ above that without radiation. This behavior is seen experimentally [88] using strongly emitting/absorbing $\mathrm{CO}_{2}$ and $\mathrm{SF}_{6}$ diluents (Fig. 18), where $S_{f}$ is higher and $\chi_{\mathrm{O}_{2}}$ lim is lower at $\mu \mathrm{g}$ than $\mathrm{lg}$, whereas the opposite (conventional) behavior is found in nonradiant diluents (not shown). These data indicate that, for nonradiating diluents, $\mu g$ is less hazardous because $\chi_{\mathrm{O}_{2} \text { lim }}$ is higher at $\mu \mathrm{g}$ than at $\lg (0.21$ vs. 0.16

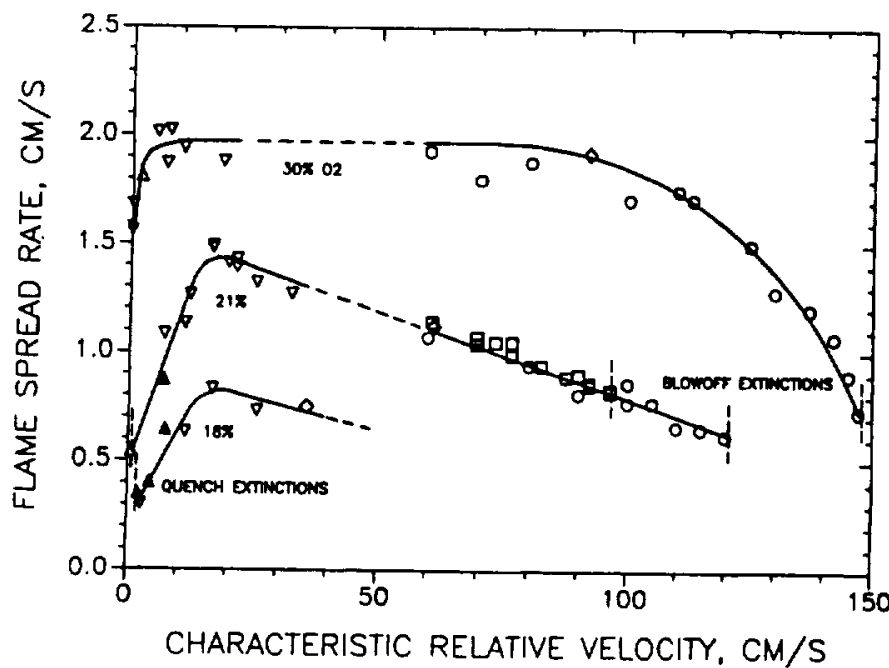

Fic. 17. Flame-spread rate over a thin solid fuel bed as a function of the opposed-flow velocity $(U)$, for three values of the mole percent $\mathrm{O}_{2}$ [85], showing dual-limit response. Note that the infinite-rate kinetics prediction $[81,82]$ that the spread rate is independent of $U$ is only satisfied at $\mathrm{O}_{2}$ mole fractions higher than that in air. 


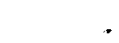




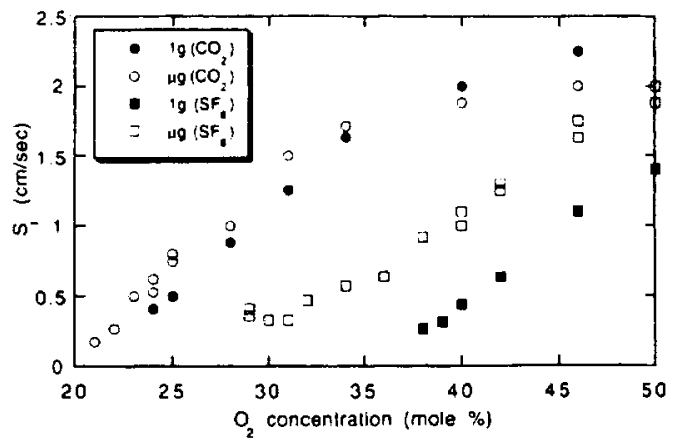

Fic. 18. Flame-spread rate over a thin solid fuel bed at $\lg$ (downward spread) and $\mu g$ as a function of $\mathrm{O}_{2}$ mole fraction [88], showing atypical behavior in $\mathrm{O}_{2}-\mathrm{CO}_{2}$ and $\mathrm{O}_{2}-\mathrm{SF}_{6}$ atmospheres where the spread rates are higher and the minimum $\mathrm{O}_{2}$ model fraction supporting combustion is lower at $\mu \mathrm{g}$

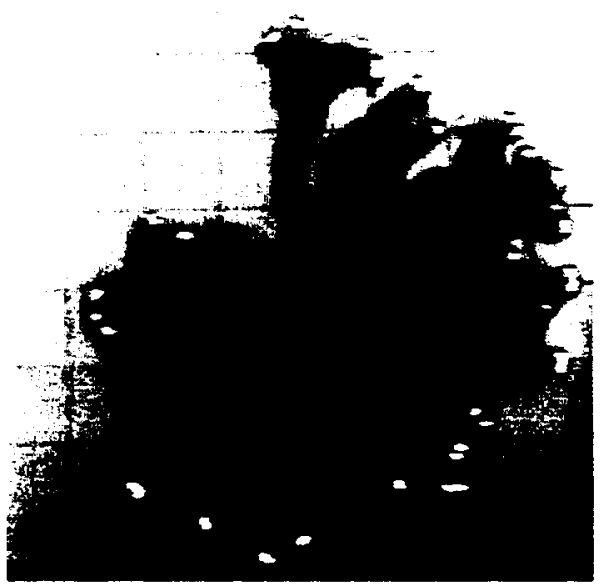

FIC. 19. Fingering patterns observed in smoldering flame spread over a thin paper fuel sample in $\mu \mathrm{g}$ [91]. Flaming combustion was inhibited by soaking the fuel sample in potassium acetate. An imposed convective velocity of $0.05 \mathrm{~m} / \mathrm{s}$ flows from right to left. Grid pattem scale is 10 $\mathrm{mm}$ by $10 \mathrm{~mm}$. Photograph courtesy of Dr. S. Olson.

for $\mathrm{He}$ ), whereas for radiant diluents, $\mu \mathrm{g}$ is more hazardous $\left(0.21\right.$ vs. 0.24 for $\left.\mathrm{CO}_{2}\right)$. This is particularly significant considering that $\mathrm{CO}_{2}$-based fire suppression systems will be used on the International Space Station. To date, flame spread calculations have employed optically thin radiation models with constant $a_{\mathrm{P}}[86,87]$ or variable depending on local temperature and composition [80] and thus cannot assess reabsorption effects.

These discussions pertain to thin fuels, for which steady $\mu \mathrm{g}$ spread is possible because theoretically $S_{f}$ $\sim U^{n}$. For thick fuels, $S_{f} \sim U^{\mathrm{t}}$, thus $S_{f}$ is indeterminate for quiescent $\mu \mathrm{g}$ conditions $\left(U=S_{f}\right.$ ). When unsteady solid-phase conduction is considered. $\tau_{\text {. }} \sim$ $\left(\alpha_{s} t\right)^{1 / 2}$, which results in $S_{f} \sim t^{-1.2}$ [89]. Consequently, all fuel beds at quiescent $\mu$ conditions eventually become thermally thin ipenetration depth greater than the bed thicknessi unless the radiative effects, discussed later, are considered. Of course, flames may extinguish due to large $\delta$ (thus large radiative loss) before reaching steady-state, thermally thin conditions.

A difficulty in comparing space experiments to two-dimensional model predictions is that the fuel bed width $I V(30 \mathrm{~mm}$ for thin fuels $[86,87]$ and 6.2 min for thick fuels [89]) is sinaller than the thermal transport zone thickness $(\delta)$. Consequently, these experiments can hardly be considered two-dimensional. Both lateral heat loss, which retards spread, and lateral $\mathrm{O}_{2}$ influx, which enhances spread, are probably important. thus their effects may partially cancel. Some authors [86] suggest that radiative losses decrease $\delta$ to values much smaller than $\alpha / C^{*}$ $=\alpha / S_{f}$, but the oxygen transport zone thickness $\left(\delta_{\mathrm{O}_{2}}\right)$ is still $D_{\mathrm{O}_{2}} / U$, because no analog to radiative loss exists for $\mathrm{O}_{2}$ transport. Because $L e=\alpha / D_{\mathrm{O}_{2}} \approx$ $1, \delta_{\mathrm{O}_{2}}$ is nearly the same as $\delta$ in adiabatic flames. Thus, the $\mu \mathrm{g}$ flames mentioned above have probably benefited substantially from lateral $\mathrm{O}_{2}$ influx, especially for lower pressures and $\mathrm{O}_{2}$ mole fractions, where $\delta / W \sim \alpha / S_{f} W$ is largest. In fact, $S_{f}$ might be higher at smaller $W$ due to lateral $\mathrm{O}_{2}$ influx. Space experiments using cylindrical fuel rods are planned $[90]$ to examine truly two-dimensional spread.

Recently, a surprising observation of fingering fronts was found in space experiments using paper samples treated to inhibit flaming combustion but allow smoldering propagation (Fig. 19) [91]. Fingering was observed at $\mu \mathrm{g}$ when $U<50 \mathrm{~mm} / \mathrm{s}$, whereas smooth fronts were observed at $\mathrm{lg}$ for all $U$. This was proposed [91] to result from limited $\mathrm{O}_{2}$ mass transport at $\mu \mathrm{g}$ with low $U$, which caused the $\mathrm{O}_{2}$ consumption regions to become localized spots instead of continuous fronts. This proposition does not explain why heat conduction does not smooth out potential fingers as it does (for example) in premixed-gas flames with $L_{e}>1$. The following alternative explanation is proposed here. Gas-phase heat transport occurs on the length scale $\delta \sim \alpha / U$, and solid-phase transport occurs on the scale $\delta_{s} \sim \alpha_{s} / u_{s}$ where $u$, is the smolder front velocity and $\alpha_{s}$ the solid thermal diffusivity. Oxygen transport occurs only through the gas phase on the scale $D_{0} / U \approx$ $\alpha U \sim \delta$. Radiative loss can suppress heat transport through the gas, but no corresponding effect on $\mathrm{O}_{2}$ transport can occur. Thus, at low $U$, the effective $L e$ is $\alpha_{s} / D_{\mathrm{O}_{2}} \ll 1$. At higher $U$ or at $1 \mathrm{~g}$, $\delta$ is smaller, gasphase heat transport dominates, and radiative effects are weaker; thus, the effective $L e$ is $\alpha / D_{\mathrm{O}_{2}} \approx 1$. These assertions are consistent with estimates [91]

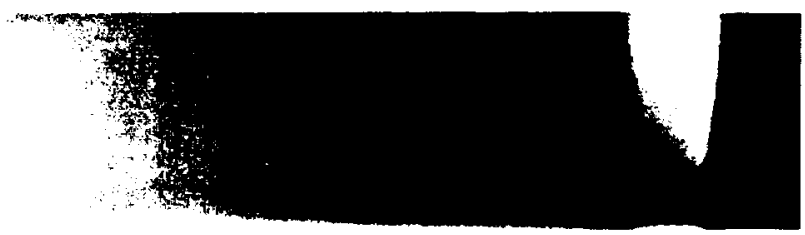


.

: . 


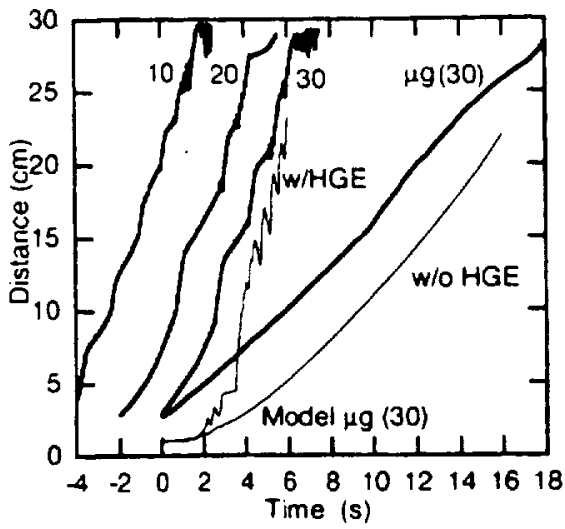

FIG. 20. Measured (thick lines) and computed (thin lines) Hame position versus time for flame spread over a 1 butanol poul 20-mm wide and 25-mun deep [97]. The 10 . 20 , and 30 notations refer to the opposed-flow velocities $(C)$ in $\mathrm{cm} / \mathrm{s}$. Both computed results are for $\mu \mathrm{g}$ conditions, $U=30 \mathrm{~cm} / \mathrm{s}$, either with or without hot gas expansion (HGE). The comparison of predicted and measured results suggests a very strong influence of expansion, which is much less effective in the experiment because of the relaxation of expansion in the transverse dimension, a factor not captured within the two-dimensional model.

of the relative importance of gas-phase and solidphase transport. Both premixed [27,39] and nonpremixed $[92,93]$ flames with effective $L e<1$ exhibit diffusive-thermal instabilities that cause fingering patterns, whereas for Le $\geq 1$, the fronts are stable. This explanation is also consistent with $\mathrm{lg}$ experiments [94] on horizontal fuel beds burning in oxidant channels of adjustable vertical height. At small heights or low $U$, fingering similar to Fig. 19 was observed. In this case, conductive loss to the channel ceiling causes suppression of gas-phase heat transfer. Apparently, in both cases, the key factor is suppression of gas-phase heat transfer while allowing solid-phase heat transfer, which reduces the effective $L e$ (though this factor was not mentioned in Ref. [91] or Ref. [94].)

\section{Flame Spread over Liquid Fuel Pools}

Flame spread over liquid fuels encompasses practically all solid-fuel flame spread phenomena discussed above, plus liquid-phase flow effects. Typically, $T_{v}-T_{x}$ is smaller for liquid than solid fuels, thus $S_{f}$ is higher. Also, if $T_{y}-T_{x}$ is small, some fuel prevaporization occurs even at $T=T_{x}$, thus partially premixed gas-phase combustion phenomena may occur. Because of the fuel surface temperature gradient upstream of the flame, surface tension gradients are produced that cause the surface layer to move upstream (away from the fane). which increases $S_{f}$. At $\mathrm{lg}$, this heated liquid laver must lie near the surface, whereas at $\mu g$, no limitation exists.

Experiments at $1 \mathrm{~g}$, summarizedin [95], show that at low fuel temperatures, the average $S_{\text {f }}$ is small (topically $10 \mathrm{~mm} / \mathrm{s}$ ) and the spread altemates between a fast "jump" velocity and a slow "crawl" velocitv. At higher fuel temperatures, $S_{f}$ is faster and steadv: For the conditions exhibiting pulsating spread at lo, $\mu g$ flame spread cannot be maintained, whereas for the conditions exhibiting uniform spread at $1 g$, steady spread is also exhibited at $\mu \mathrm{g}$ [96]. Pulsating spread has never been observed at $\mu \mathrm{g}$. No definitive explanation for these observations has been advanced. For the conditions exhibiting pulsating spread at $1 g$ and no spread at $\mu g$, flame spread is still different at $\mathrm{lg}$ and $\mu \mathrm{g}$ when forced flows comparable to buovancy-induced convection $(U=0.30 \mathrm{~m} / \mathrm{s})$ are $\mathrm{im}$ posed (Fig. 20) [97]. Specifically, Ig spread is almost unaffected by the imposed flow, but $\mu \mathrm{g}$ spread is steady with $S_{f}$ being lower $(\approx 15 \mathrm{~mm} / \mathrm{s})$ than either the $\mathrm{lg}$ jump velocity $(\approx 100 \mathrm{~mm} / \mathrm{s})$ or crawl velocity $(\approx 22 \mathrm{~mm} / \mathrm{s}$ ).

Detailed numerical modeling [98] predicts pulsating spread at $\mu \mathrm{g}$ for the conditions of Fig. 20 and values of $S_{f}$ much closer to the measured $\mathrm{lg} S_{f}$. Remarkably, if thermal expansion is artificially suppressed, good agreement between the model and $\mu \mathrm{g}$ experiments is found. It is proposed [97] that this agreement results from three-dimensional effects; specifically, in the experiment, flow induced by thermal expansion is relaxed in the lateral dimension, whereas the two-dimensional model does not permit this. That three-dimensional effects might dominate is surprising considering that, for this flame, $\delta / W-$ $\alpha / U W \approx 0.02$, thus, $\delta \ll W$. Also, this hypothesis does not explain why pulsating flame spread is observed at $\mathrm{lg}$ but not $\mu \mathrm{g}$. Consequently, in the case of liquid-fuel flame spread, $\mu g$ experiments have identified limitations in our current understanding of combustion processes at $\mathrm{ig}$.

\section{Recommendations for Future Studies}

\section{Reabsorption Effects}

The $\mu g$ studies described here suggest new unresolved issues and opportunities for further improvements in understanding. Perhaps the most important are the effects of reabsorption of emitted radiation, including both reabsorption by the emitting gas and, in two-phase combustion, absorption by the condensed phase. All radiative effects discussed above are critically dependent on the degree of reabsorption. To study reabsorption effects requires radiatively active diluents $\left(\mathrm{CO}_{2}, \mathrm{SF}_{6}\right)$, high pressures and or large systems. All of these conditions lead to higher $G r_{d}$ at $\mathrm{lg}$ and thus turbulent flow. Hence, $\mu \mathrm{g}$ 
experiments enable study of reabsorption effects without the additional complications due to turbulence.

Reabsorption effects are important not only to $\mu \mathrm{g}$ studies but also to combustion at high pressures and in large combustors. For example, at $40 \mathrm{~atm}$, typical of premixed-charge internal combustion engines. $a_{p}$ $\approx 18 \mathrm{~m}^{-1}$. thus, $a_{p}^{-1}=0.045 \mathrm{~m}$. for stoichiometric combustion products. Because this length scale is comparable to cylinder radii, reabsorption effects within the gas cannot readily be neglected. Simple estimates [99] indicate radiative loss may influence flame quenching by turbulence in lean mixtures. Similarly, reabsorption cannot be neglected in atmospheric-pressure furnaces larger than $a_{\bar{p}}^{-1} \approx 2.2$ $\mathrm{m}$. Moreover, many combustion devices employ exhaust-gas or flue-gas recirculation; for such devices, the unburned mixtures contain significant amounts of absorbing $\mathrm{CO}_{2}$ and $\mathrm{H}_{2} \mathrm{O}$.

Although reabsorption of emitted radiation could affect practically all types of flames reviewed here. to date. reabsorption effects have been studied only for propagating premixed-gas flames $[24,26]$, flame balls [45], and flame spread over thermally thin fuels [88]. All have shown substantial differences from optically thin behavior. Two examples of effects expected for other flames are given below.

Reabsorption effects could be substantially more important for droplet combustion than for Hame spread over solid fuels because for droplets, the Stefan flow severely limits heat conduction to the droplet surface. This is why heat release $(B)$ affects burning rates $(K)$ only weakly (logarithmically) (equation $8)$. Radiative transfer is unaffected by the Stefan flow. Equation 8 is readily extended to include surface radiative flux $\left(q_{r}\right)$ :

$$
\Omega=\ln \left(1+\frac{B}{1-R / \Omega}\right) ; R=\frac{q_{\mathrm{r}} d_{\mathrm{d}} C_{P}}{2 \lambda L_{v}} ; \Omega=\frac{K \rho_{\mathrm{d}} C_{P}}{8 \lambda}
$$

Figure 21 shows the predictions of equation 11 . (Although equation 11 has apparently not been presented previously, numerical studies $[100,101]$ have shown qualitatively similar predictions. Moreover, these studies show that typical radiative absorption lengths for liquid fuels at relevant wavelengths are on the order of $1 \mathrm{~mm}$, thus large droplets could absorb most incident radiation.) For spherical shells of radiant combustion products having thickness $\delta \ll$ $d_{f}, q_{r} \approx A \delta / 4$, then for typical values $B=8.5, A=$ $2 \times 10^{6} \mathrm{~W} / \mathrm{m}^{3}, \delta=10 \mathrm{~mm}, d_{\mathrm{d}}=5 \mathrm{~mm}, C_{y}=$ $1400 \mathrm{~J} / \mathrm{kgK}, \lambda=0.07 \mathrm{~W} / \mathrm{mK}$, and $L_{\mathrm{v}}=400 \mathrm{~kJ} / \mathrm{kg}$, equation 11 predicts $R=0.63$ and $\Omega / \Omega_{R-0}=1.11$; thus, moderate effects of radiative transfer are expected. For droplets in radiatively active diluents such as $\mathrm{CO}_{2}$, the effect could be much stronger. Using the $\mathrm{PI}$ approximation, for a sphere of unit emissivity in an infinite gray gas, $q_{\mathrm{r}}=[4 /(2+3$
$\left.\left.a_{P} d_{1} / 2\right)\right] \sigma\left(T^{4}-T_{x}^{*}\right\}[102]$. Using volume-alveraged properties $T=1(0) 0 \mathrm{~K}$ and $a_{P(1)}=20 \mathrm{ml}, R=$ 18 and thus $\Omega / \Omega_{\mathrm{R}=11}=8.0$. indicating radiation dominates heat transport. As discussed later, at high pressures radiative effects may prevail esen in $\mathrm{O}_{2}$ $\mathrm{N}_{2}$ atmospheres.

Flame spread over thermally thick fuel beds in quiescent atmospheres at $\mu g$ is typically considered inherently unsteady [89], however radiative transfer to the fuel bed could enable steady spread. If the flame is modeled by an isothermal volume with dimensions $\delta \times \delta \times W$, radiation induces a radiative flux $A \delta^{2} W=A\left(\alpha^{2} / S_{f}^{2}\right) W$ that augments the conductive flux $i(\delta W)\left(T_{f}-T_{v}\right) / \delta$. Equating this total heat transfer to $\rho_{s} C_{P_{v},} \tau_{v}\left(T_{v}-T_{x}\right) W S_{f}$ vields

$$
S_{f}=\left[\frac{A \alpha_{g}^{2}}{\sqrt{\alpha_{u} \rho_{s} C_{P_{s}} \lambda_{s}}\left(T_{v}-T_{x}\right)-\lambda_{,}\left(T_{l}-T_{v}\right)}\right]^{12}
$$

which vanishes without gas radiation $(A=0)$. Thickfuel space experiments in $\mathrm{O}_{2}-\mathrm{CO}_{2}$ or $\mathrm{O}_{2}-\mathrm{SF}_{6}$ atmospheres could be employed to check for steady spread and test the accuracy of equation 12.

Whereas optically thin radiation modeling is reasonably straightforward, modeling of spectrally dependent emission and absorption is challenging because local fluxes depend on the entire radiation field, not just local scalar properties and gradients. Some relevant computations have employed graygas models [74], but recent studies $[26,103]$ show that these methods are probably inaccurate because of the wide variation in spectral absorption coeffcient with temperature, species, and wavelength. Comparisons of various radiative treatments for small one-dimensional non-premixed flames have been made [103]. Comparisons for larger, multidimensional systems would be valuable. Moreover, recent studies of $\mu \mathrm{g}$ soot formation $[52,56,57]$ may enable improved modeling of soot radiation at $\mu \mathrm{g}$.

\section{High-Pressure Combustion}

All practical combustion engines operate at pressures much higher than atmospheric. The impact of buoyancy for premixed flames scales as $t_{\text {chemr }} / t_{\text {is }} \sim$ $\left(g \alpha / S_{L}^{3}\right)^{2 / 3} \sim P^{n-4 / 3}$, where $n$ is the overall reaction order $\left(S_{\mathrm{L}} \sim P^{n / 2}-1\right)$. Because, typically, $n<4 / 3$ for weak mixtures [104], where buoyancy effects are most important, the impact of buoyancy increases with pressure. Also, as discussed earlier, radiation effects are more difficult to assess at higher pressure due to increased interference from buoyant transport. Nevertheless, few high-pressure $\mu \mathrm{g}$ combustion experiments have been performed. High-pressure droplet combustion experiments [10.5] revealed substantial but different increases in $K$ with $P$ at $1 g$ and $\mu g$. Radiative effects were not discussed but could have been important, because in equation 11 . 



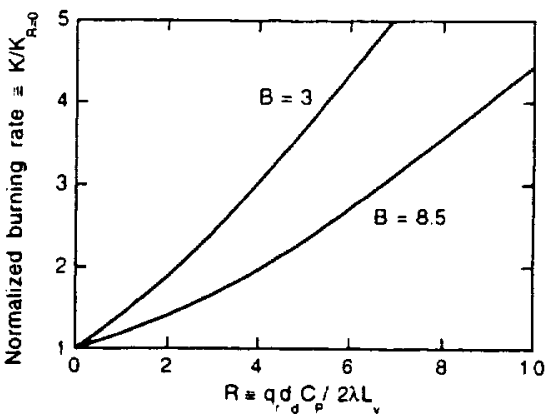

FiG. 21. Predicted effect of radiative heat transport coefficient $(R)$ on droplet burning rate constant referenced to the value without radiative transport, showing importance of absorption of radiation at the droplet surface on the resulting burning rate. $B=3$ and $B=8.5$ are characteristic of methanol and heptane, respectively, burning in adr.

the only pressure-dependent factor is $q_{r} \sim A \sim P^{i}$. thus in Fig. 21, $R \sim P$. (For most flames, length scales decrease with increasing $P$, which would decrease radiative effects; but for droplet flames, $d_{f}$ depends only on stoichiometry $[75,76]$.) Consequently, further assessment of radiative effects in high-pressure droplet combustion and other types of fames appears warranted.

\section{Three-Dimensional Effects}

In earlier sections, effects of lateral heat and mass transport on flame spread were discussed. To assess three-dimensional effects, $\mu \mathrm{g}$ experiments with varying fuel bed width $(W)$ are needed. Complementary three-dimensional modeling using codes such as those developed by NIST [106], extended to include gas-phase radiation, would be instructive. An approximate but much less expensive approach would be to incorporate volumetric terms $6 \lambda\left(T(x, y)-T_{x}\right) /$ $W^{2}$ and $6 \rho D_{i}\left(Y_{i}(x, y)-Y_{i, x}\right) / W^{2}$, where $x$ and $y$ are the coordinates parallel and perpendicular to the fuel bed, into the two-dimensional model to account for lateral heat losses and lateral diffusion of each species $i$.

Another three-dimensional effect is found in the development of flame balls from ignition kemels. Currently, it is known that large flame balls are linearly unstable to three-dimensional disturbances for weak loss (Fig. 5), but the transition from splitting flame balls to stable flames is not well understood, nor can the number of flame balls produced from an ignition source be predicted. Modeling using threedimensional premixed flame codes [107] is needed.

\section{Gas-Jet Flames}

Table 2 shows predicted scalings of flame lengths $\left(L_{f}\right)$ and residence times $\left(t_{\text {jet }}\right)$ for buoyant and nonbuoyant round-jet and slot-jet flames. Despite numerous investigations of round-jet flames at $\mu \mathrm{g}$, no $\mu g$ slot-jet results are available to test those predictions. Currently, it is unknown whether slot-jet fames at $\mu g$ would exhibit smoke points or whether this information could be used to explain smoke points in $\mu g$ round-jet fames. Because $L_{f}$ depends on $g$ for buoyant slot-jet but not round-jet flames. $L_{f}$ should be quite different at $l g$ and $\mu g$ for slot-jets but not round-jets. Residual accelerations in aircraft $\mu g$ experiments will be more problematic for slot-jet than round-jet flames because $t_{j+t} \sim g^{-1 / 2}$ for buoyant round-jet flames whereas $t_{j, t} \sim g^{-1 / 3}$ for slot-jet Aames.

There has been little investigation of blow-off behavior of laminar gas-jet flames at $\mu \mathrm{g}$. Dual-limit behavior might occur for flames of fixed-mass flow rate but varying $d_{0}$, with short residence time extinction at small $d_{0}\left(t_{\mathrm{jet}} \sim d_{i}^{2} / U_{0}\right)$ and radiative extinction at large $d_{\mathrm{o}}$ (thus, large $t_{\mathrm{j}+\mathrm{t}}$ ). Experiments should be conducted by diluting the fuel rather than increasing $C_{\text {, }}^{\prime}$ to obtain blow-off without transition to turbulence. In this way, dual-limit behavior has been observed at $\lg$ [92] with short residence time and conductive loss (to the burner rim) extinction branches.

\section{Quasi-Steady Spherical Diffusion Flames}

As discussed previously, comparing predicted radiative extinction limits of droplet flames to experiments is problematic because quasi-steady conditions may not be obtained, because extinction occurs for sufficiently large droplet and flame diameters, but the droplet diameter decreases throughout its life. Numerical models can account for transient effects, but the multidimensional ignition process is difficult to model quantitatively. Comparisons of droplet experiments and computations to corresponding results obtained using fuel-wetted porous spheres would be most interesting. The fuel should be forced through the porous sphere at slowly increasing rates until extinction occurs when $d_{f}>$ $\left(\alpha t_{\text {rad }}\right)^{1 / 2}$, thus obtaining truly quasi-steady extinction. Long $\mu$ g durations would be required to establish steady diffusion-dominated far-field temperature and composition profiles (thus, steady radiative loss). Some preliminary results have been obtained in aircraft experiments [108] but were severely compromised by the residual $g$ levels. Candle flames are similar to wetted porous spheres, though without true spherical symmetry or any means to control or measure the instantaneous $d_{\mathrm{d}}$.

A simpler related experiment employs porous spheres through which gaseous fuel is forced at prescribed $\dot{m}$, resulting in a flame diameter $d_{f} \approx \dot{m} C_{P}$ $2 \pi \lambda \ln (1+f)$. Some drop-tower experiments using this configuration have been reported $[109,110]$, although steady-state conditions were not obtained due to short $\mu$ g durations. Steady-state behavior appears unlikely given the $\dot{m}$ (thus, air consumption rates) and chamber sizes employed to date; near-wall 
oxgen depletion would be significant over the times required to reach steady-state $(\geq 10$ s $[110])$. Steadystate behatior might be obtained in drop-towers by using smaller $m$ ind diluted fuel with enriched oxvgen atmosphere's to increase f and thus decrease $d_{f}$ and $t_{\text {, }(r, m)} \sim d ?$

\section{Catulytic Combustion}

Catalytic combustion holds promise for reduced emissions and improved fuel efficiency in many combustion systems $[111,112]$. Because catalysis occurs at surfaces. it is inherently multidimensional and/or unsteady, requining reactant transport to the surface and heat and products transport from the surface Although boundary-layer approximations can be invoked, probably the only truly one-dimensional steady catalytic configuration is a spherical surface immersed in nonbuovant quiescent premixed gasa "catalytic fame ball." In this case, $r_{f}$ is fixed but the surface temperature $T_{\mathrm{s}}$ and fuel concentration $Y_{s}$ are unknown. These are related through the energy conservation (including surface radiation) and diffusion equations to obtain the surface reaction rate in moles per second $(\boldsymbol{\theta})$ :

$$
\begin{aligned}
& \Theta\left(Y_{\mathrm{s}}, T_{\mathrm{s}}\right)=\rho_{\mathrm{s}} D_{\mathrm{s}} r_{\mathrm{v}} Y_{\mathrm{x}}\left(1-Y_{\mathrm{s}} \mathcal{X}_{\mathrm{x}}\right) / M \\
& \frac{Y_{\mathrm{s}}}{Y_{\mathrm{z}}}=1-L e\left(\frac{T_{\mathrm{s}}-T_{\mathrm{x}}}{T_{\mathrm{dd}}-T_{\mathrm{x}}}\right)\left(1+\frac{\sigma \varepsilon_{\mathrm{s}} r_{\mathrm{s}}\left(T_{\mathrm{s}}^{4}-T_{\mathrm{x}}^{4}\right)}{\lambda_{\mathrm{s}}\left(T_{\mathrm{s}}-T_{\mathrm{x}}\right)}\right)
\end{aligned}
$$

where $\varepsilon_{\mathrm{s}}$ is the surface emissivity and properties with the subscript $s$ are evaluated at $T=T_{\mathrm{s}}$. By varying $r_{s}, Y_{x}$, pressure, and diluent gas, $\Theta(T, Y)$ can be inferred from equation 13 and the measured $T_{\mathrm{s}}$. Of course, conditions must be unfavorable for initiation of propagating flames or flame balls that stand off from the surface.

\section{Chemical Models}

An important contribution of $\mu g$ combustion experiments has been improved understanding of extinction processes, which are inherently related to finite-rate chemistry. To obtain closure between experiments and computations, accurate chemical models are needed. For lean premixed hydrocarbonair flames, most models $[21,26]$ predict higher $S_{L}$ and leaner flammability limits than experimental observations $[22,33,113]$. The discrepancy seems larger than experimental uncertainty or unaccounted heat losses could explain. In contrast, for $\mathrm{H}_{2}$-air flame balls [4.5] and $\mathrm{lg}$ strained premixed $\mathrm{H}_{2}$-air flames [114], these chemical models predict smaller balls, lower $S_{L}$, and richer flammability limits than experiments. These chemical models predict $S_{\mathrm{L}}$ in mixtures away from extinction limits very faithfully. The discrepancies result largely from differences in rates for $\mathrm{H}+\mathrm{O}_{2}+\mathrm{M}$ reactions, particularly the Chaperon efficiencies of various if species [4.5]. These reactions are extremely important in nearlimit flames due to competition between chanbranching and chain-inhibiting steps near limits [21] but are much less important away from linits. Further scrutiny of the rates for these reactions at intermediate temperatures $(1100-1400 \mathrm{~K})$ would be welcomed.

\section{Conclusions}

Our understanding of combustion fundamentals has been broadened by $\mu$ g experiments into regimes not previously explored. In particular, these experiments have helped integrate radiation into flame theory. Although flame radiation has long been recognized as an important heat-transfer mechanism in large fires [115], its treatment has largely been ad hoc because of the difficulty of predicting soot formation. Also, large-scale fires at $1 g$ are inevitably turbulent, leading to complicated flame-flow interactions. Small-scale $\mu \mathrm{g}$ flames are laminar, often soot-free, and have significant influences of radiation. As a result of radiation effects, both premixed and non-premixed flames have exhibited dual-limit extinction behavior, with residence time-limited extinction at high strain, or curvature and radiative loss-induced extinction at low strain or curvature. The high-strain limit is readily observed at $1 \mathrm{~g}$; when forced flow is absent, buoyant flow causes this strain. For weak mixtures, these limits converge, but the convergence and the entire low-strain extinction branch can only be seen at $\mu g$. This dual-limit behavior is observed for stretched and curved premixed-gas flames, strained non-premixed flames, isolated fuel droplets, and flame spread over solid fuels. Besides radiative effects, $\mu \mathrm{g}$ studies have enabled observation and clanification of numerous other phenomena, for example, thermophoresis effects in soot formation, spherically symmetric droplet burning, diffusion-controlled premixed flames (Hame balls), and flame instabilities in droplets and candle flames. Considering the rapid progress made recently, further advances are certain to occur. It is hoped that this report on the current state of understanding will help motivate and inspire such advances.

\section{Nomenclature}

Planck mean absorption coefficient flame surface area transfer number (chemical enthalpy generation/enthalpy needed for fuel evaporation)

$c_{\mathrm{s}} \quad$ stoichiometric molar ratio of fuel to air $C_{P} \quad$ constant-pressure heat capacity 
d characteristic flow-length scale or tube diameter

dr droplet fame dianeter

$l_{d} \quad$ droplet dianieter

$d_{l_{1},} \quad$ droplet initial diameter

$d_{0} \quad$ jet exit diameter (round jets) or slot width (slot jets)

D mass diffusinity

$E$ overall activation energy of the heat-release reactions

$g$

Gr

$G r_{d}$

$h$

$H$

stoichiometric fuel to air mass ratio

acceleration of gravity

earth gravity

Grashof number based on characteristic length scale $(d)=g d^{3} / v^{2}$

heat transfer coefficient in a cylindrical tube $=16 \mathrm{~N} d^{2}$

radiative loss parameter for flame spread $=t_{\mathrm{di} \mathrm{f}^{\prime}} / t_{\mathrm{rit} l}=\alpha / L^{n-t_{r, \mathrm{kl}}}$

$K$ droplet burning rate constant (equation 8 )

$L_{f} \quad$ flame length for gas-jet flame

$L_{\mathrm{I}} \quad$ turbulence integral scale

$L_{v} \quad$ latent heat of vaporization of liquid fue

Le Lewis number ( $\alpha / D=$ thermal diffusivity/ reactant mass diffusivity)

$\dot{m} \quad$ mass burning rate

M fuel molecular weight

$P \quad$ pressure

$r \quad$ radial coordinate

$r_{f}$ flame radius

$R$

$R_{\mathrm{g}}$
$R \boldsymbol{e}$

Sf

$S_{\mathrm{L}}$

$S_{\mathrm{L}, \mathrm{iin}}$

$S c$

$t_{\text {chern }}$

$t_{\text {diff }}$

$t_{\text {drop }}$

$t_{\text {inv }}$

$t_{\text {jet }}$

$t_{\text {rad }}$

$t_{\mathrm{sis}}$

$T$

$T_{\text {ad }}$

$u^{\prime}$

$U$

$U_{y}$

$U_{\mathrm{o}}$

w

$\stackrel{y}{\mathrm{Y}}$

$\alpha$

$\beta$ scaled flame radius (eq 6); radiation parameter (eq 11)

gas constant

jet Reynolds number $=U_{v} d_{d} / v$

flame spread rate over solid fuel bed

premixed laminar burning velocity

burning velocity at the flammability limit

Schmidt number $=v / D$

chemical time scale

thermal diffusion time scale $=\alpha / U^{2}$

droplet flame time scale $=d \frac{9}{f} / \alpha$

inviscid buoyant transport time scale

residence time of non-premixed jet flame

radiative loss time scale

viscous buoyant transport time scale

temperature

adiabatic flame temperature

turbulence intensity

convection velocity

local axial velocity in counterflow configuration

jet exit velocity

gas-jet flame width

solid fuel bed width

axial coordinate

fuel mass faction

thermal diffusivity

nondimensional activation energy $=$ $E / R_{\mathrm{q}} T_{\text {f }}$ \%).lim minimum oxyen concentration supporting combustion

flane thickness

gas specific heil ratio

thermal conductivity

radiative heat loss per unit volume = $t \sigma a_{p}\left(T_{i}^{4}-T^{4}\right)$

kinematic viscosity

density

fuel bed half-thickness (thin fuel) or thermal penetration depth (thick fuel)

$\sigma \quad$ Stefan-Boltzmann constant

$\Sigma \quad$ Hame stretch rate

\section{Subscripts}

d droplet surface condition

f flame front condition

s solid-fuel or solid-surface condition

$\checkmark \quad$ solid- or liquid-fuel vaporization condition

$\infty \quad$ ambient conditions

\section{Acknouledgments}

The author expresses his deepest gratitude to the VASALewis Research Center for supporting his $\mu \mathrm{g}$ combustion work for more than 10 years. Comments from Tom Avedisian, Yousef Bahadori, John Buckmaster, .Mun Choi, Dan Dietrich, Fred Dryer, Gerard Faeth, Guy Joulin, Yiguang Ju, Kaoru Maruta, Vedha Nayagam, Takashi Niioka, Sandra Olson. Howard Ross, Kurt Sacksteder, Dennis Stocker, Peter Sunderland, Gregory Sivashinskv, James Tien, Karen Weiland, Forman Williams, and anonymous reviewers have been invaluable in preparing this paper. The author also thanks numerous others who offered useful suggestions that could not be accommodated because of space limitations.

\section{REFERENCES}

1. Sacksteder, K. R., in Twenty-Third Symposium (Intemational) on Combustion. The Combustion Institute, Pittsburgh, 1990, pp. 1589-1597.

2. Law, C. K. and Faeth, G. M., Prog. Energy Combust. Sci. 20:65-113 (1994).

3. Microgravity Combustion Science: 1995 Program Update, NASA TM-106858, 1995.

4. Kono, M., et al., in Tuenty-Sixth Symposium (International) on Combustion, The Combustion Institute. Pittsburgh, 1996, pp. 1189-1199.

5. Coward, H. and Jones, C., U.S. Bureau of Mines Bulletin 503 (1952)

6. Giovangigli, V. and Smooke, M., Combust. Sci. Technol. 87:241-256 (1992).

7. Levy, A., Proc. R. Soc. London A283:134-145 (1965)

8. Wang, Q. and Ronney, P. D., "Mechanisms of Flame Propagation Limits in Vertical Tubes," Spring Tech. nical Meeting, Eastern/Central States Section of the 

The Combustion Institute. New Orleans, LA, March 15-17. 199.3 Paper No. 45.

9. Buckumaster, J. D and Mikolaitis, D. Combrast. Flame t5: 109-119 (1982).

10. Kriuulin. V. N. Kudryavtsev, E. A., Baratov, A. N. Badalyan, A. M. and Babkin. V. S.. Combust. Expl. Shock Waies 17:37-41 (1981).

11. Jarosinsky, J., Strehlow, R. A., and Azarbarzin, A., in Virreteenth Symposium (International) on Combustion, The Combustion Institute, Pittsburgh, 1982. pp. 1549-1557.

12. Patnaik. G. and Kailasanath, K., in Twenty-Fourth Symposium (Intemational) on Combustion, The Combustion Institute, Pittsburgh, 1992, pp. 189-195.

13. Spalding, D. B., Proc. R. Soc. London A240:83-100 (1957).

14. Buckmaster, J. D., Combust. Flame 26:151-162 (1976).

15. Joulin. G. and Clavin, P., Acta Astronautica 3:223240 (1976).

16. Jarosinsky, J., Combust. Flame 50:167-175 (1983).

17. Aly, S. L. and Hermance, C. E., Combust Flame 40:173-185 (1981).

18. Williams, F. A.. Combustion Theory, 2nd ed. Benjamin-Cumming, Menlo Park, 1985.

19. Abbud-Madrid, A. and Ronney, P. D., in TwentyThird Symposium (Intemational) on Combustion, The Combustion Institute, Pittsburgh, 1990, pp. 423431.

20. Lakshmisha, K. N., Paul, P. J., and Mukunda, H. S., in Tuenty-Third Symposium (International) on Combustion, The Combustion Institute, Pittsburgh, 1990. pp. $433-140$.

21. Law, C. K. and Egolfopoulos, F. N., in TuentyFourth Symposium (International) on Combustion, The Combustion Institute, Pittsburgh, 1992, pp. 137144.

22. Ronney, P. D., in Tuenty-Second Symposium (International) on Combustion, The Combustion Institute, Pittsburgh, 1988. pp. 1615-1623.

23. Strehlow, R. A. and Reuss, D. L., in Combristion Experiments in a Zero Gravity Laboratory (T. H. Cochran. ed.). Progress in Aeronautics and Astronautics, vol. 73, AIAA, New York, 1981, pp. 61-89.

24. Abbud-Madrid, A and Ronney, P.D., AIAA J 31:2179-2181 (1993).

25. Joulin, G. and Eudier, M., in Twenty-Second Symposium (Intemational) on Combustion. The Combustion Institute, Pittsburgh, 1988, pp. 1579-1585.

26. Ju, Y., Masuya, G., and Ronney, P. D., in Tuenty-Seventh Symposium (International) on Combustion, The Combustion Institute, Pittsburgh, 1998, pp. 26192625.

27. Clavin, P. Prog. Energy Combust. Sci. 11:1-59 (1985).

28. Ronney, P. D. and Sivashinsky, G. I., SIAM J. Appl. Math 49:1029-1046 (1989).

29. Ronney, P. D., Combust. Sci. Technol. 59:123-141 (1988).

30. Farmer, J. R. and Ronney, P. D., Combust. Sci. Technol. 73:555-574 (1990).
31. Lewis, B. and von Elbe, G., Combustion. Flames, and Explosions of Cases, 3rd ed., Academic Press. Orlando. FL, 1987.

32. Buckmaster. J. D. and Mikolaitis, D., Combust. Flame 47:19l-204 (1982).

33. Guo, H., Ju, Y.. Manuta, K., Niioka. T., and Liu, F., Combust Flame 109:639-646 (1997).

34. Ju, Y., Guo, H., Liu, F. and Maruta, K. Fluid Wech, in press.

35. Buckmaster, J. D., Combust. Theory Modeling 1:111 (1997).

36. Zeldovich, Ya. B., Theory of Combustion and Detonation of Gases, Academy of Sciences (USSR). Moscow, 1944.

37. Deshaies, B. and Joulin, G., Combust. Sci. Technol. 37:99-116 (1984).

38. Buckmaster, J. D. and Weeratunga, S., Combust. Sci. Technol. 35:287-296 (1984)

39. Ronney, P. D., Combust. Flame 82:1-14 (1990).

40. Ronney, P. D., Whaling, K. N., Abbud-Madrid, A., Gatto. J. L., and Pisowicz, V. L., AlAA J. 32:569-57i (1994).

41. Ronney, P. D., Wu, M. S., Weiland, K. J., and Pearlman, H. G., AIAA J. 36:1361-1368 (1998).

42. Buckmaster, J. D., Joulin, G. and Ronney, P. D., Combust. Flame 79:381-392 (1990).

43. Lee, C. and Buckmaster, J. D., SIAM J. Appl. Math. 51:1315-1326 (1991).

44. Buckmaster, J. D.. Smooke, M., and Giovangigli, V., Combust. Flame 94:113-124 (1993).

45. Wu, M. S., Lu. J. B., and Ronney, P. D., in TuentySeventh Symposium (Intemational) on Combustion. The Combustion Institute, Pittsburgh, 1998, pp. 2543-2550.

46. Maruta, K., Yoshida, M., Guo, H., Ju, Y., and Niioka, T., Combust. Flame 112:181-187 (1998).

47. Jost, W., Explosions and Combustion Processes in Gases, McGraw-Hill, New York, 1946.

48. Roper, F., Combust. Flame 29:219-226 (1977).

49. Haggard, J. B. and Cochran, T. H., Combust. Sci. Technol. 5:291-298 (1972).

50. Sunderland, P. B., Mendelson, B. J., Yuan, Z. G., and Urban, D. L., Combust. Flame 116:376-386 (1999).

51. Bahadori, M. Y., Stocker, D. P., Vaughan, D. F., Zhou, L. and Edelman, R. B., in Modern Developments in Energy Combustion and Spectroscopy (F. A. Williams, A. K. Oppenheim, D. B. Olfe, and M. Lapp, eds.), Pergamon Press, 1993, pp. 49-66.

52. Urban, D. L., Yuan, Z. G., Sunderland. P. B., Voss, J. E., Lin, K. C., Dai, Z., Sun, K., and Faeth, G. M., AIAA J. 36:1346-1360 (1998).

53. Hottel, H.C. and Hawthome, W. R., in Third Symposium (International) on Combustion. The Combustion Institute, Pittsburgh, Williams \& Wilkins, Baltimore, 1949, pp. 254-266.

54. Hedge, U., Yuan, Z. G., Stocker, D., and Bahadori, M. Y., in Proceedings of the Fourth Intemational Microgravity Combustion Workshop, NASA Conference Publication 10194, 1997, pp. 185-190. 
55. Pitts, WV. M., in Tiventy-Second Sympoxitum /liternational) on Combustion. The Combustion Institute. Pittsburgh, 1958. pp. \$1)9-\$16.

56. Creenberg, P. S and Ku, J. C.. Combust. Flame 108:207-2:30) (1997)

57. Sunderland, P. B., Mortazavi, S., Faeth, G, M., and Urban. D L.. Combust. Flame 96:97-103 (1994).

58. Glassman, I. in Tuenty-Second Sympasimm inter. national on Combustion, The Combustion Institute. Pittsburgh, 1988. pp. 295-311.

59. Mortazavi, S., Sunderland, P. B., Jumg, J, Köylü, U. D., and Faeth, G. W., ALAt paper 93-078 1993.

60. Fujita, O., Ito, K., Ito, H., and Takeshita, Y., in Proceedings of the Fonuth International Micrograxity Combustion Workshop, NASA Conference Publication $10194,199 \pi$, pp. $217-222$

61. Kumagai, S. and Isoda, H., in Sirth Symposium (Intemational) on Combustion. The Combustion Institute, Pittshurgh, 1957, pp. 726-731.

62. Spalding, D. B., in Fourth Symposium(International) on Combustion. Williams \& Wilkins, Baltimore, 1953, pp. $847-864$

63. Godsave G. A. E., in Fourth Symposium (International) on Combustion, Williams \& Wilkins, Baltimore, 1953, pp. 818-830

64. Chao, B. H., Law, C. K., and T'ien, J. S., in TuentyThird Symposium (International) on Combustion, The Combustion Institute, Pittsburgh, 1990, pp. 523531 .

65. Cheatham, S. and Matalon, M., in Twenty-Sixth Symposium (International) on Combustion. The Combustion Institute, Pittsburgh, 1996, pp. 1063-1070.

66. Dietrich, D. L., Dryer, F. L., Haggard, J. B., Nayagam, V., Shaw, B. D., and Williams, F. A., in TuentySixth Symposium (International) on Combustion, The Combustion Institute, Pittsburgh, 1996, pp. 12011207.

67. Nayagam, V., Haggard, J. B., Colantonia, R. D., Marchese, A. J., Dryer, F. L., Zhang, B. L. and Williams, F. A., ALAA J. 36:1369-1378 (1998)

68. Choi, M. Y.. Drver, F. L., and Haggard, J. B., in Tuenty-Third Symposium (Intemational) on Combustion. The Combustion Institute, Pittsburgh, 1990 , pp. 1597-1604.

69. Jackson, G. S. and Avedesian, C. T., Proc. R. Soc London A446:255-276 (1994).

70. Marchese, A. J., Dryer, F. L., and Nayagam, V., Combust. Flame 116:432-459 (1999).

71. King, M. K., in Tuenty-Sixth Symposium (Interna tional) on Combustion. The Combustion Institute, Pittsburgh, 1996, pp. 1227-1235.

72. Shaw, B. D., Dryer, F. L., Williams, F. A., and Haggard, J. B., Acta Astronautica 17:1195-1202 (1988).

73. Jackson, G. S., Avedesian, C. T., and Yang. J. C., Int J. Heat Mass Transfer 35:2017-2033 (1992).

74. Cho, S. Y., Choi, M. Y., and Dryer, F. L., in TwentyThird Symposium (International) on Combustion, The Combustion Institute, Pittsburgh, 1990, pp 1611-1617.
75. Yang, J. C. Jackson, G. S., ind Avedesian. C. T. in Tuconty-Third Symposium (Intermational) on Combustion. The Combustion Institute. Pittsburgh. 1990 pp. 1619-1625.

76. Nawagam. V. and Williams. F. d., in Setenth International Conference on Numerical Combustion. Societv for Industrial and Applied Mathematics, Philadelphia, PA, 1998. p. 46.

77. Dietrich, D. L., Ross, H. D, and T'ien. J. S., AIAA paper 9-4-0429

78. Dietrich, D. L., Ross, H. D., Frate. D. T. Tien, J. S., and Shu, Y., in Proceedings of the Fourth International Microgracity Combustion Workshop. NASA Conference Publication 10194, 1997, pp. 237-242.

79. Buckmaster, J. D. Combust. Sci. Technol. 115:41-68 (1996).

S0. Grayson, G. D., Sacksteder, K. R., Ferkul, P. and T'ien, J.S., Microgratity Sci. Technol T:187-195 (1994).

91. deRis, J. N., in Twelfth Symposium (International Ion Combustion. The Combustion Institute, Pittsburgh, 1968, pp. 241-252.

82. Delichatsios, M. A. Combust. Sci. Technol. 44:25T267 (1986)

83. Olson, S. L., Ferkul, P. V., and Tien. I. S., in TuentySecond Symposium (International) on Combustion, The Combustion Institute. Pittsburgh, 1988, pp 1213-1222.

84. Rhatigan, J. L., Bedir, H., and T'ien, J S., Combust. Flame 112:231-241 (1998).

85. Olson, S. L., Combrust. Sci. Technol. 76:233-249 (1991).

86. Ramachandra, P. A., Altenkirch, R. A., Bhattacharjee S., Tang, L., Sacksteder, K., Wolverton, M. K., Combust. Flame 100:71-84 (1995)

87. Bhattacharjee, S., Altenkirch, R. A., and Sacksteder, K., J. Heat Transfer 118:181-190 (1996).

88. Honda, L and Ronnev, P. D., Combust. Sci. Technol. 133:267-291 (1998).

89. West, J., Tang, L., Altenkirch, R. A., Bhattacharjee, S., Sacksteder, K., Delichatsios, M. A., in TwentySixth Symposium (International) on Combustion. The Combustion Institute. Pittsburgh, 1996, pp. 13351343

90. Bhattacharjee, S., Altenkirch, R. A., Worley, R., Tang, L., Bundy, M., Sacksteder, K., Delichatsios, M. A., in Proceedings of the Fourth International Microgracity Combustion Workshop, NASA Conference Publication 10194, 1997, pp. 387-392.

91. Olson, S. L., Baum, H. R., Kashiwagi, T., in TuentySeventh (Intemational) Symposium on Combustion. The Combustion Institute, Pittsburgh, 1998, pp $2525-2533$

92. Chen, R. H., Mitchell, G. B., Ronney, P. D., in Twenty-Fourth (Intemational) Symposium on Combustion. The Combustion Institute, Pittsburgh, 1992. pp. 213-221.

93. Kim, J. S., Williams, F. A., and Ronney, P. D., J. Fluid Mech. 327:273-302 (1996). 


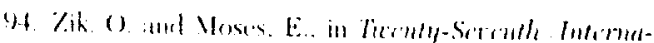

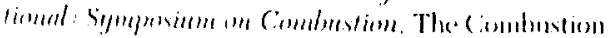

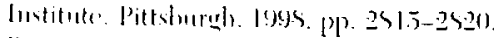

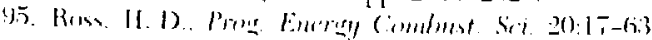
$11 \% 4:$

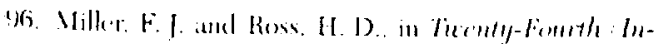

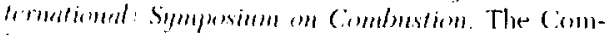

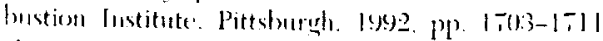
1940 ?

97. Roxs. H. D, and Milter. F. J. in Tuenty-Sivth Sigm-

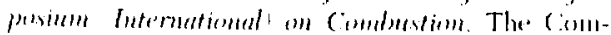
Instion Institute. Pittsburgh, 1996. pp. 13:27-13334 19061

Us Schiller, D X. Russ. H. D. and Sirignamo. W A.. Combust Soi. Tochmol 115:20)3-25.5 1996).

99. Remner. P. D. in Vedeling in Combustion Sichere J. D. Buckmister and T Takemo, eds.), Lecture Vintes In Phssics wol +49. Springer-Verlag, Berlin. $1595, \mathrm{pp}, 3-2.2$

100. Chin. H. H. and Chang, S. S. AIAt palper 9.3-2194.

101. Chang. K C. and Shiclı. J. S. Int. J Hot Mass Trmesfor $24: 2611-2621$ a 1945 )

102. Sieurel. R. and Howell. J. R. The mal Radiation Hot Transfor. Brel ed. Hemisphere. Washington. D.C. 1992.

10:3. Bectir, H.. Tien. J. S., and Lee. H. S., Combust. Theany Modeling 1;395-41) (1997)

(1) t. Egolfipmolos. F. X. and Law. C. K., Combust. Flame S(): $\bar{i}-16,19(0))$

10.5. Viezlle. B.. Chimean. C., Chesneau. X. Odeide, A. Gokialp. I. in Tuenty-Sixth Sympositum inteniaciomal on Combustion. The Combustion Institute. Pittshurah. 1996. pp. 1259-126.5.

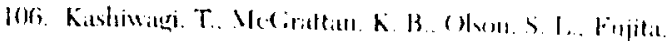

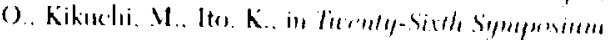

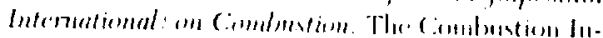

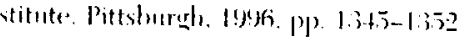

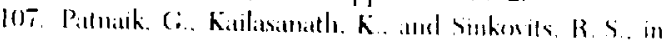

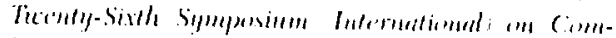

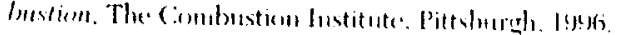

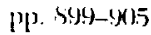

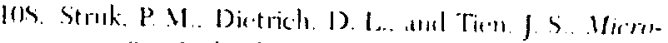

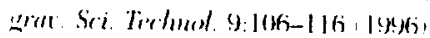

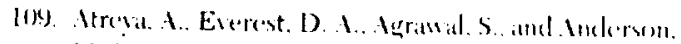

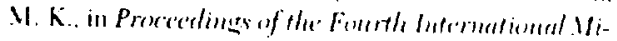

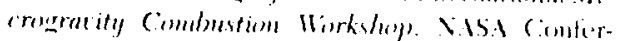

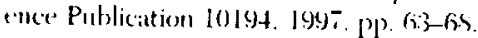

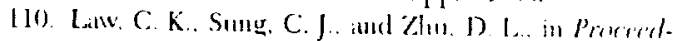

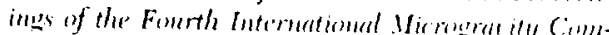

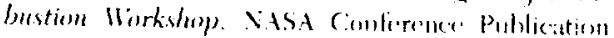
10194. Iyst. pp. rig-it.

111. Pfelferle, W. C and Pfilferle. L. D. Prous Eures Comburst. Sci. I 2:25-41 1946i).

112. Wamatz. J., in Ticenty-Fonth Symponime lutemer tional) an Comberstion. The Cimbustion lustitute Pittsburgh, 1992, pp. 55:3-579

113. Ronney, P. D., Commlust. Flame 62: 1:2)-132 : 19451.

114. Egolfopoulos, F. N and Law. C. K. in Tienty-Third Symprasiam (International on Combustion. The Combustion Institute. Pittsburgh, 1994. pp. $113-121$.

115. Williams, F. A., in Sixte'neh Symposiam International) on Combustion. The Combustion Institute Pittsburgh. 1976. pp. 12S1-1294.

\section{COMMENTS}

H. S. Mukunda, Lidian Institute of Science, Bangalore, India. In your presentation. you credited the computational clemonstration of the result on the absence of a flammability limit in adiabatic flames to Giovangigli and Snooke [1]. This result was first obtained in 1989 [2]. You might like to amend the citation suitablv.

\section{REFERENCES}

1. Gionangigli, V. and Snooke, M. Combust. Sci. Technol. $5-241$ i 19921 .

2. Lizkshmisha. K. N. et al., in Tecenty-Second Symposium Intenutionalion Combustion. The Combustion Institute. Pittsburgh, 1958. pp. 15\%3-15\%.

futhor's Reply. In this earlier paper by the questioner and his collaborators [?]. it was shown that the solutions of the unstealy planar one-dimensional allabatic premixed Hame equations do not predict any hammability limit for lean $\mathrm{CH}_{4}-\mathrm{O}_{2}-\mathrm{N}_{2}$ mixtures - the burning velocity decreases assmptotically to zero as the mixture strength is decreased. In Smooke and Gionangigli (Ref. [1] of the comment), the steady version of these equations was solved for $\mathrm{CH}_{4}$-air and $\mathrm{H}_{2}$-air mixtures, and a similar conclusion was reached. Both are important findings, because it is possible in principle that unsteady effects could suppress limits of steady. flames or cause limits to occur for mistures that are flanmable as steady flames. Together they show that one must identify loss mechanisms of the appropriate magnitude to explain Hannability limits, which was one of the key points of my presentation.

J. P. Gore. Purdue Lnicersity, CSA. Yon seem to have drawn a conclusion based on vour time-scale antalysis that "radiation is not important at $1 \mathrm{~g}$." For combustion under high-pressure conditions, for fires (large and small), and for all flames as far as high activation energ reaction steps are involved, radiation can be potentially importint. Could you please re-examine and clarify sour conclusion regarding radiation not being important at $1 \mathrm{~g}$ ?

Author's Reply. Certainly radiation is an important mechanism of heat transfer in flames even at $1 \mathrm{~g}$-large 
$-\quad$ $+$. 


\section{INITED PIENARY I.ECTLRE.}

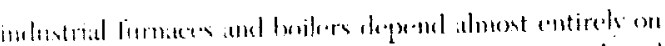

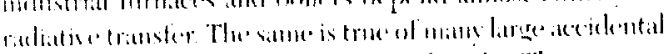

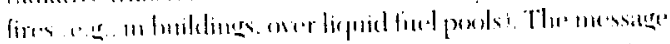

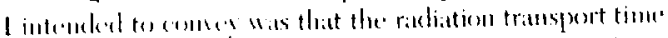

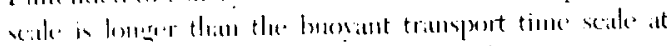

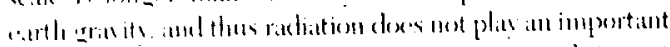

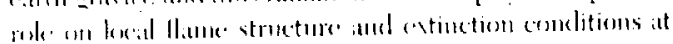

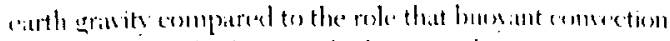

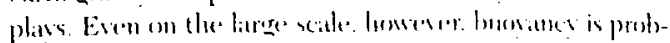

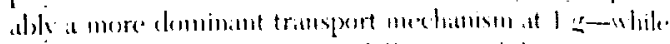

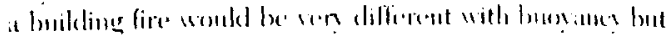

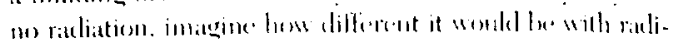
attion but no burenatucs! 
. 